\title{
Vibrotactile localization on the arm: Effects of place, space, and age
}

\author{
ROGER W. CHOLEWIAK and AMY A. COLLINS \\ Princeton University, Princeton, New Jersey
}

\begin{abstract}
Although tactile acuity has been explored for touch stimuli, vibrotactile resolution on the skin has not. In the present experiments, we explored the ability to localize vibrotactile stimuli on a linear array of tactors on the forearm. We examined the influence of a number of stimulus parameters, including the frequency of the vibratory stimulus, the locations of the stimulus sites on the body relative to specific body references or landmarks, the proximity among driven loci, and the age of the observer. Stimulus frequency and age group showed much less of an effect on localization than was expected. The position of stimulus sites relative to body landmarks and the separation among sites exerted the strongest influence on localization accuracy, and these effects could be mimicked by introducing an "artificial" referent into the tactile array.
\end{abstract}

How is spatial information processed by the sense of touch? A pat on the back or the touch of a mosquito on the arm both appear to be localized quickly and accurately. There are, however, many less natural situations in which complex tactile patterns are presented by elaborate communication systems. In these cases, in order for useful intercourse to occur, the stimuli have to be appreciated with speed and accuracy. In the case of sensory disability, the sense of touch is often recruited to substitute for, or to augment, the remaining senses, and the information that it is required to process is typically encoded in a spatial display. For example, a person who is blind must make very fine spatial discriminations with the fingertips in order to read Braille (Foulke, 1982; Hollins, 1989; Millar, 1985). The appreciation of such static patterns challenges the ability of the skin to resolve touches presented near one another. The measure of this ability is the so-called two-point limen, and it has been the topic of considerable exploration and occasional controversy among sensory psychologists for over 170 years. In De Tactu and Der Tastsinn, Weber (1826/1978) reported a number of studies of spatial localization on several body sites, describing parameters (including orientation and body site) that appeared to affect localization and acuity. Boring (1942, p. 475ff.) has an extended discussion of tactile acuity and localization, including the changes that occur with extended practice, the 121 ways of localizing

This study and the preparation of this manuscript was supported by NIH Grant DC 00076 and ONR Grant N00014-95-1-0387to Princeton University, R.W.C., P.I. The authors express their appreciation to Lauren Cesaro, Heather Stamberger, and Steven Cholewiak for their assistance in collecting and processing the data from these experiments and to Carl E. Sherrick for his constructive comments on the manuscript. Correspondence concerning this article should be sent to R. W. Cholewiak or A. A. Collins, Department of Psychology, Green Hall, Princeton University, Princeton, NJ 08544-1010 (e-mail: rcholewi@ princeton.edu). cutaneous points, as well as the influences of body site. Hamburger (1980) in his remarkable dissertation, described in some detail the many studies that, in fact, have used many of these techniques, as well as the presumed underlying neurology. Site was also a primary parameter for Weinstein (1968), who explored localization for paired touch stimuli over the surface of the body in considerable detail, and the figures describing his data appear in virtually every basic textbook. Stevens and his colleagues (Stevens, 1992; Stevens, Foulke, \& Patterson, 1996; Stevens \& Patterson, 1995) continued in this tradition, while addressing important methodological issues raised by Johnson and his colleagues, who questioned the traditional methods of measuring spatial acuity (Craig \& Johnson, 2000; Johnson \& Phillips, 1981; Johnson, Van Boven, \& Hsiao, 1994). They recalled Tawney's (1895) critique of the interpretation of two-point data that tactile "extensity" can occur without two points (p. 592), suggesting that subject bias plays such an important role in these judgments that modifications in methodology and instrumentation were warranted. Current data now indicate that the highest acuity for spatial touch stimuli exists at body sites that are the most highly innervated (or at least, have the most dense spacing among receptors; Craig \& Lyle, 2002) and in the skin of younger versus older persons.

Despite the long history of these inquiries, these data have been obtained only with pressure or static stimulation, using points, bars, or gratings that are touched or pressed into the skin. The majority of the devices that are currently used in cutaneous communication systems, however, use stimuli that vibrate, rather than just contact, the skin briefly. For example, the Optacon is a text-processing system that allows people who are blind to read printed text at rates of 60-100 wpm (manufactured by Telesensory Sensory, Inc., from 1970 to 1995). With this device, text is read by a hand-held camera and presented to the 
user through a 144-pin array of vibrators touching the fingertip. Another vibratory communication aid is the Tactile Situation Awareness System, a body-worn device that presents information to users with spatial vibrotactile patterns on customized arrays consisting of 24-96 tactors (Raj, McGrath, Rochlis, Newman, \& Rupert, 1998; Raj, Roetzer, Fatolitis, Cholewiak, \& Kass, 2001; Rupert, 2000; Rupert, Guedry, \& Reschke, 1993). In this case, the information encoded tactually might be environmental (an approaching target or obstacle), vestibular (the attitude of an aircraft in three-dimensional space), or positional ("up" or "down" in the International Space Station). Yet another class of such devices is the Tactaid-7 (Audiological Engineering Corp.), one of several commercially available tactile aids used by people who are deaf to augment lipreading skills. It processes the acoustic speech waveform and transforms it into a vibrotactile spatial pattern presented on an array of seven vibrators, typically placed along the forearm. With this device, concurrent processing of the tactile analogue of the acoustic waveform with the visual image of speech production has been shown to improve comprehension by as much as $40 \%$ (Weisenberger, 1992; Weisenberger \& Percy, 1995). But all of these devices require appreciation of dynamic vibrating spatial patterns, and in no case has there been a systematic exploration of localization accuracy for the array of tactors. It is unlikely that the data in the literature, based on pressure or touch stimuli, will provide definitive answers to the question of how well the vibrating sites can be localized in the spatial domain. When the skin is vibrated, the stimulus can travel for many centimeters, depending on the body site and the stimulus frequency. In their classic work, Franke and his colleagues (Franke, von Gierke, Oestreicher, \& von Wittern, 1951), as well as Keidel (1968) and Oestreicher (1951), examined traveling waves propagating over the surface of the body, resulting from vibration of the skin. These waves are similar to the circular waves resulting from dropping a stone in water and, depending on a number of physical factors, can produce measurable motion on the skin's surface many centimeters from the vibrating source. A static surround may damp the spread of surface waves (Gescheider, Capraro, Frisina, Hamer, \& Verrillo, 1978), but not those passing through deeper tissues, where many of the cutaneous receptors lie, although the extent of the stress and strain deformations are somewhat more attenuated (Greenspan \& Bolanowski, 1996; Pubols, 1987). Unlike water waves, these are a function of the viscoelastic properties of the skin. The velocity of traveling waves in the human skin depends not only on the elasticity of the skin itself, but also on vibration frequency, skin temperature, and whether underlying tissue is bone, fat, muscle, or a combination.

To further complicate the issue, the skin is far from a uniform receptive organ. Unlike the somewhat homogeneous distribution of receptor structures arrayed over the surface of the retina or cochlea, the arrangement of identified receptors in the skin appears to vary considerably, not only through its depth, but across the surface as well. For example, the glabrous or smooth skin of the palm of the hand has structures that differ from those in the hairy skin over the majority of the body (Greenspan \& Bolanowski, 1996, Figure 1), and like the three types of cones in the retina, each of these structures responds to stimuli having a slightly different character from one another (Bolanowski, Gescheider, \& Verrillo, 1994; Bolanowski, Gescheider, Verrillo, \& Checkosky, 1988; Cholewiak \& Collins, 1991). When the skin is vibrated, the stimulus not only is spatial, but also has specific temporal characteristics, and its effect depends on how those characteristics interact with the site stimulated. For example, in smooth skin, four different receptor channels have been isolated, each sensitive to a separate frequency range (Bolanowski et al., 1988). The specific structures are less well defined in hairy skin (Bolanowski et al., 1994), but they similarly show response characteristics that differ from one another. Consequently, tactile vibratory sensitivity will be influenced by where, as well as how, one stimulates the skin. This can be seen in Wilska's (1954) study with $200-\mathrm{Hz}$ stimuli, a rare demonstration of this variation in sensitivity over the body's surface. In addition, however, exploration of the characteristics of the structures responsible for tactile sensitivity (at least on glabrous skin) reveals that each of these channels has its own particular spatial response characteristics as well. Microneurographic data, such as those collected by Vallbo and Johansson (1984), show that cutaneous receptive fields, similar to those in higher-order visual cells, may encode complex spatial information. Single neural units may receive information from areas of the skin as small as $1 \mathrm{~mm}$ in diameter (Meissner "Fast-Adapting I" or Merkel "Slowly-Adapting I" channels), they could have receptive areas as large as a finger (Pacinian "FastAdapting II"), or they may even be directionally sensitive (Ruffini "Slowly-Adapting II") channels. Johnson and Hsiao's (1992) single-unit data from these different receptor populations show how spatial information from the environment can be processed in dramatically different ways, depending on which channel is stimulated. Thus, variations in location might profoundly affect the processing of tactile information as we move from body site to body site. So any analysis of spatial localization on the body must take into account the place on the skin that is stimulated, the distance or space between stimulators, and the frequency of stimulation.

But there is one more factor to be considered here: the age of the observer. Systems and devices designed to be used to compensate for sensory disability, such as those that occur with failing visual or vestibular senses, will likely be used by aged persons, because they are the population in which the majority of these conditions occur. However, as with the other sensory modalities, touch also deteriorates over time. Reviews of the changes that occur in the skin with aging have pointed out substantial losses in sensitivity to touch or vibratory stimuli, particularly after the age of 20 , just as occurs with vision and 
audition (e.g., Kenshalo, 1979, 1986; Stevens, 1992; Verrillo, 1979, 1980, 1982, 1993). Typically these studies have been concerned with measuring pressure or vibrotactile thresholds (e.g., Frisina \& Gescheider, 1977; Pearson, 1928; Verrillo, 1980; Whanger \& Wang, 1974), although tactile discrimination has also been studied. In most cases, there is a decline in the examined capacity (e.g., Goble, Collins, \& Cholewiak, 1996). That is, thresholds increase, or discriminative capabilities are poorer, in older individuals. However, Goble et al. did find that despite the reduction in detection threshold with age, changes in that threshold as a function of two spatial manipulations (contactor area and presence of a rigid surround) were identical in the two age groups. Similarly, Gescheider, Edwards, Lackner, Bolanowski, and Verrillo (1996) also reported a decline in sensitivity with age, whereas there was no effect of age on suprathreshold intensitive difference limens (DLs). A few notable studies have shown similar declines in performance in complex measures of tactile pattern processing, such as haptic or form exploration (Axelrod \& Cohen, 1961; Coté \& Schaefer, 1981; Kleinman \& Brodzinsky, 1978), spatial acuity (Stevens, 1992), or temporal processing (Van Doren, Gescheider, \& Verrillo, 1990). The underlying cause of the progressive loss has usually been attributed to physiological changes in the skin itself (e.g., Steinberg \& Graber, 1963; Stevens, 1992; Verrillo, 1979) or neurological factors (Lindblom \& Verrillo, 1979; Mirsky, Futterman, \& Broh-Kahn, 1953; Wahren \& Torebjork, 1992). The functional decline in tactile perceptual skills also parallels age-related anatomical and morphological changes in the skin and its receptors. In aging skin, the size, shape, and number of cells in the upper layers become quite variable, and glands often atrophy or become inactive (Montagna, 1965). Interestingly, dramatic agerelated alterations in some mechanical properties of the skin, such as compliance, however, do not appear to be tied to reductions in tactile sensitivity (Larkin, Reilly, \& Kittler, 1986; Woodward, 1993). Changes with aging in the receptors themselves have also been fairly well documented (for a review, see Goble et al., 1996). In general, while number decreases, structural complexity increases. For example, there are one third as many Meissner corpuscles in some body sites in 70-year-old individuals as in 20-year-old persons (Schimirgk \& Rüttinger, 1980; Winkelmann, 1965; Zelená, 1994). In addition, there are fewer Pacinian corpuscles, and those that remain undergo dramatic modifications in shape and size, whereas Merkel's disks and free nerve endings undergo less obvious changes with age (Cauna, 1965). Because these structures and others have been related to different aspects of tactile sensitivity (Bolanowski et al., 1988; Johnson \& Hsiao, 1992; Phillips, Johansson, \& Johnson, 1992), a correlation would be expected between these changes and variations in tactile acuity. Cauna, for example, suggested that if the density of Meissner corpuscles is related to touch thresholds and spatial discrimination, measures of spatial acuity should vary system- atically from decade to decade (they do; Stevens, 1992; Stevens et al., 1996). Similarly, there is a progressive reduction in tactile sensitivity to high-frequency stimulispecifically, over the optimal range processed by Pacinian corpuscles (Verrillo, 1980). There are also decreases in temporal-processing abilities with aging. For example, the appreciation of temporal gaps in vibratory stimuli (important in audition for the understanding of speech) was found to be poorer in elderly individuals (Van Doren et al., 1990), and persistence effects, resulting from prior tactile stimulation, were also more pronounced in older persons (Gescheider, Valetutti, Padula, $\&$ Verrillo, 1992).

Significant theoretical implications can be drawn from our understanding of the spatial encoding by individual receptor structures and their patterns of aging. Stevens and his colleagues (Stevens et al., 1996; Stevens \& Patterson, 1995) argued that the reduction that they measured in static tactile acuity with age has serious consequences for blind persons trying to read Braille characters. Another implication that one might draw is that high-frequency stimuli, appealing to deeper lying Pacinian receptors, would be poorly localized, especially in an older population. Yet we are unaware of studies of the changes that occur in vibrotactile spatial localization over the age span, except for preliminary data from this laboratory that have shown differences in pattern identification performance between older and younger subjects that appear to be directly related to poorer spatial resolution in the older group (Cholewiak \& Collins, 1993, 1995). Performance level and acquisition rates for spatial patterns, presented with $250-\mathrm{Hz}$ sinusoids on a linear array of four tactors spaced $5.0 \mathrm{~cm}$ apart on the forearm, were inversely related to pattern complexity. Most older individuals $(60+$ years of age) were able to learn to reliably identify only simple one-element patterns, essentially localizing the generating tactors, but not a combination of those. Students, however, in the same task, mastered even three- to four-element patterns. Whereas tactile pattern perception requires a combination of both spatial- and temporal-processing abilities, in the present research we primarily examined spatial-processing abilities, to indicate the types and directions of change in this sensory capacity in older subjects, relative to the younger student population.

Remarkably few studies have pursued these theoretical implications to determine vibrotactile spatial localization or acuity at the particular sites used in the tactile communication aids or research devices described above, despite the fact that the majority of the information these devices provide lies in their spatial encoding. The reasonable question can be asked as to whether the lessthan-optimal performance typically seen with such systems might be related to a mismatch between the spatial acuity of the skin and the resolution of the device. There are only a few notable studies of tactile resolution in which the ability to localize vibrotactile stimuli has been specifically examined. In attempts to determine the spacing for tactors in the Tactile Vision Substitution System, 
Eskildsen, Morris, Collins, and Bach-Y-Rita (1969) explored simultaneous and successive two-point thresholds on the lateral back near the scapula for 2-sec 60-pps pulsatile stimuli, finding that threshold could be as small as $11 \mathrm{~mm}$ for pairs of 1-mm contactors (Weinstein's, 1968, static two-point thresholds were approximately $4 \mathrm{~cm}$ ). Rogers (1970) examined spatial resolution on the fingertip, with two constantly vibrating tactors spaced 2-10 mm apart. For frequencies of 10 and $250 \mathrm{~Hz}$, resolution was a function of separation, with poorest performance at $2 \mathrm{~mm}$, although the potential influence of adaptation resulting from such durative stimuli was not addressed. Hill (1970) did show that increasing the spacing between elements on a linear display could improve pattern recognition.

In a more direct test of localization as a function of tested receptor population, Sherrick, Cholewiak, and Collins (1990) used carefully controlled $25-$ or $250-\mathrm{Hz}$ stimuli to appeal to high- and low-frequency sensitive cutaneous channels. Observers indicated the location of a burst of vibration on the hypothenar eminence of the palm (the edge opposite the thumb). Over 7-mm contactor separations from 10 to $30 \mathrm{~mm}$, localization accuracy was generally above $75 \%$, although low-frequency stimuli were only slightly better localized. But to our knowledge, vibrotactile spatial acuity data do not exist in a form as uniform as those for static touch collected by Weinstein (1968) or Stevens (1992). Sans data, Geldard (1960) and Gilmer (1966) stated simply that the acuity for vibration is poorer than that for simple touch for any given region and that "no one really knows how many [vibrotactile] loci can be distinguished simultaneously" (Gilmer, 1966, p. 8). The situation has not changed much since Gilmer's report. It is our aim to provide some of these data in pattern-processing tasks, including studying the changes in processing that occur as a consequence of the normal aging process. Our hypotheses were that (1) the ability to localize vibrotactile stimuli would depend on site of application (place) and proximity of other active sites (space), as well as on stimulus parameters such as vibration frequency, and (2) that the performance of the college student population would be similar to that for individuals 60 years of age or older, except that the levels would be poorer for the older group.

In the experiments to be described here, we intended to explore a number of these issues, using vibrotactile localization as the experimental paradigm. After preliminary measurements of the sensitivity at a number of sites on the forearm, localization ability was examined on a linear vibrotactile array for stimuli presented at two different frequencies over seven sites. The effect on localization of place of the array on the body, relative to particular body landmarks, was explored in the second experiment. With the third experiment, we describe the effect of nonanatomical reference sites on localization, whereas spacing of sites was manipulated in the fourth experiment. Stimulus frequency and age of the observer were parameters in all of the experiments to be described.

\section{GENERAL METHOD}

\section{Human Subjects}

The subjects were drawn from the population of 18- to 30-yearold students at the University, as well as from a population of senior citizens, 60 years of age or older, recruited from the community at large through newspaper advertisements, presentations at senior centers, and word of mouth. The observers were accepted without regard to gender, race, nationality, or ethnic origin. They were in good health, as evidenced through a medical questionnaire that surveyed conditions and medications that could affect tactile sensitivity. The subjects signed informed consent forms, were able to discontinue participation at any time, and were paid a nominal honorarium after each experimental session. The specific numbers of observers are listed in the description of each experiment. Procedures and protocols were approved by the Princeton University Institutional Review Panel.

\section{Body Sites}

The site explored in the experiments on localization was the volar surface of the forearm. The volar forearm, like the majority of the body, is hairy skin with a complement of receptors that is different from those on the glabrous skin of the hand (Bolanowski et al., 1994). It provides a continuous, relatively flat surface to study, permitting the separation of stimulators by as much as $25 \mathrm{~cm}$. This site has been used to explore the efficacy of several tactile aids (e.g., the Queens aid and the Tactaid-7; Weisenberger \& Percy, 1995). The points tested in the present experiments fell on a medio-lateral line centered on the volar forearm when it was resting on a tabletop, starting at a point $8 \mathrm{~cm}$ from the elbow and separated by $2.5 \mathrm{~cm}$. This is the same distance that separates the individual vibrators in the Tactaid-7 array described earlier and in the linear array used in the present experiments.

For the preliminary threshold study, the thenar eminence of the palm was also tested to ensure "normal" sensitivity. The thenar is the large pad on the palm that lies between the thumb and the wrist, and a large number of studies have examined tactile sensitivity in this area of the hand (e.g., Verrillo, 1985).

\section{General Procedures}

The observers were comfortably seated at a desk facing a visual display for instructions and feedback. A small audio unit for auditory feedback and a response keyboard were also on the desk. Circumaural headphones were worn, through which white noise was presented to mask distracting ambient or cuing sounds from the stimulators. Skin temperature was measured at a central location on each site to be examined and was maintained within the range of $31^{\circ}-37^{\circ} \mathrm{C}$ for this and the following experiments, in order to stabilize sensitivity (e.g., Green, 1977; Stevens, 1990; Verrillo \& Bolanowski, 1986). The left hand and volar forearm were exposed and oriented so as to be available for stimulation. Sandbags stabilized and immobilized the test site prior to the experiment. Prior to every session with the linear array, vibrotactile threshold for the array was measured, as will be described in detail later. Responses were made by pressing designated buttons on a keypad, while other keystrokes moved the observer through the testing series. For incentive and task training, where appropriate, a feedback tone was sounded after each response (high-pitched if correct, low if incorrect), and the correct answer was presented on the visual display.

\section{Preliminary Measurements: Vibrotactile Thresholds on the Hand and Forearm}

The tactile arrays used in the experiments on localization employed tactors distributed over the length of the arm at sites similar to those stimulated by the vibrators in the Tactaid-7. Descriptions in the literature of a number of measures, such as tactile pressure thresholds or two-point limens, have suggested that sensitivity increases over this distance as more distal sites are stimulated (e.g., 
Békésy, 1960, Figures 13-37; Boring, 1942, Figure 80; Cholewiak \& Collins, 1991, Figures 2-13). Boring also discusses Vierordt's (1870) "law of mobility," which argued that thresholds change continuously along limbs, with a change in the slope of the function as joints, such as the wrist or elbow, are crossed. Although vibrotactile thresholds have occasionally been recorded at individual sites on the arm or wrist (e.g., Verrillo, 1966; Wilska, 1954), a systematic, quantitative series of measurements has not been done over its whole length. Because stimuli, such as those to be studied here, could be localized on the basis of gross differences in perceived magnitude, resulting from varying sensitivity over the seven loci, it was deemed necessary to measure thresholds at the sites to be tested in the later experiments.

Vibrotactile detection threshold stimulus. Stimuli were generated with a Bruel \& Kjaer 4810 mini-shaker fitted with a PCB $303 \mathrm{a}$ accelerometer. The accelerometer served as the contactor while displacement and the waveform of the signal were monitored. The 7-mm-diameter $\left(0.38 \mathrm{~cm}^{2}\right)$ contactor was centered in a $9-\mathrm{mm}$ hole in a support plate mounted in the tabletop so as to provide a surround having a 1-mm gap (see Gescheider et al., 1978). The shaker was mounted on a balance arm so as to provide approximately 60 gm of force when it was placed against the skin. With this force, the tip of the contactor protruded approximately $0.5 \mathrm{~mm}$ above the surface of the surround when loaded by the thenar, ensuring firm contact with the skin (e.g., Verrillo, 1966, Figure 4). The timing of stimuli presented by the shaker was controlled by a computer interface connected to a Grason-Stadler Model 829 electronic switch that shaped and gated the sinusoidal output of the Exact 626 function generators controlled with an IEEE-488 GPIB interface. The intensity (as well as the frequency) of the signal could be varied with the programmable function generators on a trial-by-trial basis. The switches provided for $25-\mathrm{msec}$ rise-fall times for the shaped 500-msec bursts of vibration, minimizing onset/offset transients that could provide spurious activation of high-frequency receptor channels. The switches directed the signals to a Bruel \& Kjaer 2706 amplifier driving the mini-shaker. Stimulus amplitude was controlled over a $60-\mathrm{dB}$ range by the computer, while a set of user-controlled in-line attenuators was available to extend this range and allow for finer adjustments. For further details, see Goble et al. (1996). Seven sites on the forearm were tested, distributed from the elbow to the wrist.

Adaptive forced-choice tracking protocol. In order to evaluate vibrotactile thresholds, a bias-free forced-choice tracking paradigm was used (Hautus \& Lee, 1998; Johnson \& Phillips, 1981; Stevens \& Patterson, 1995; Zwislocki, Maire, Feldman, \& Rubin, 1958). In this psychophysical technique, three intervals occurred in every trial. The target stimulus (a burst of vibration) was presented in only one of the intervals, and the task of the observer was to identify that interval. This forced-choice design was coupled with a transformed adaptive algorithm: If the response was incorrect, the intensity of vibration was raised in the next trial. If the target interval was correctly identified, stimulus magnitude was decreased, but according to a predetermined schedule that depended on the prior sequence of correct responses. The approximate range of threshold was initially approached with a modified procedure having larger step sizes and a looser criterion for reducing magnitude. After three reversals, a more stringent rule was imposed. Specifically, whenever the observer was incorrect, the magnitude of the variable parameter was increased by $1 \mathrm{~dB}$ (approximately 10\%), whereas the observers were required to respond correctly three times in a row in order for the magnitude to be decreased. The criterion used to terminate the series was performance based: The stimulus was tracked until 12 up-down transitions occurred, and threshold was defined as the mean of the stimulus magnitudes over the last 7 transitions (see Stevens \& Patterson, 1995). The stimulus level for each trial was automatically determined by a computer program that recorded responses and calculated all relevant statistics. The schedule pro- duced convergence on the psychometric function at approximately $78 \%$ (Levitt, 1971). Threshold displacements were calculated from the average acceleration measured while the system was under load, touching the skin.

Vibrotactile detection threshold procedure. In order to ensure that the individual observers did not have abnormal vibrotactile sensitivity, threshold was first measured on the left thenar eminence with three frequencies of sinusoidal stimuli $(50,120$, and $250 \mathrm{~Hz}$ ), because of the large literature on sensitivity at this site. A complete thenar testing session consisted of six blocks of trials (two repetitions of each frequency), and the observers returned for two sessions. The data from 29 senior observers and 31 college-age subjects were entirely consistent with studies of vibratory threshold on this site in the literature. These data revealed that threshold depended on the stimulus frequency $[F(1,58)=453.913, p<.01]$, with the lowest threshold levels at higher frequencies. Furthermore, the senior subjects were found to be less sensitive than their younger counterparts $[F(1,58)=61.503, p<.01]$, as Gescheider, Bolanowski, Hall, Hoffman, and Verrillo (1994), Goble et al. (1996), and Verrillo (1993) found. The averages obtained over the repetitions at each frequency also showed considerable variation in sensitivity across observers within an age group, although as Stevens and Patterson (1995) have described, this variation was found to be greater within the older population. In a few of these cases, the functions were quite flat, showing no effect of frequency at all. None of the potential subjects, students or seniors, needed to be excluded because of abnormal thenar threshold functions.

Threshold on the left volar forearm was measured with two frequencies of sinusoidal stimuli (100 and $250 \mathrm{~Hz}$ ). A complete forearmtesting session consisted of seven blocks of trials at one of the two frequencies, one measurement block per location. There were two sessions per frequency for students and three for seniors. The order of frequencies presented during the sessions was counterbalanced over subjects. When threshold sensitivity was measured at a number of sites that ranged along the whole length of the volar forearm, the patterns of findings were generally consistent with those on the thenar. These seven locations on the forearm were the same sites as those at which testing was done throughout the rest of the research. Mean thresholds measured by the adaptive forced-choice tracking procedure from 11 senior observers and 21 college-age subjects are shown in Figure 1. A signif icant difference was found between the $100-\mathrm{Hz}$ and the $250-\mathrm{Hz}$ thresholds for both the younger subjects and the seniors $[F(1,30)=53.953, p<.01]$ : Thresholds for $250-\mathrm{Hz}$ stimuli were lower. The difference between the thresholds measured at both frequencies was larger for the students than for the seniors $[F(1,30)=8.334, p<.01]$. In addition, thresholds for the senior population were higher than those for the student populations $[F(1,30)=78.450, p<.01]$, as was expected. Both findings support the idea that sensitivity to higher frequency vibration is more affected by aging than are stimuli that appeal best to "non-Pacinian" receptors (Bolanowski et al., 1988). Interestingly, the variation in threshold over these sites along the arm was minimal: There was no significant main effect of location on the arm for students or seniors. [The senior data did show a significant interaction between frequency and location- $F(6,60)=3.054, p<.05$ - but the differences in performance levels were minimal and displayed no strong pattern of results.] This is an important (and unexpected) finding, because it indicates that (1) there is no increase in sensitivity over the proximo-distal extent of the array, (2) perceived magnitude should not play a large role in localization over the sites chosen, and (3) these data appear to violate Vierordt's (1870) "law of mobility," described earlier!

\section{Measurements of Vibrotactile Localization on the Forearm}

Vibrotactile localization stimulus. For the majority of the rest of the experiments, the same seven locations along the forearm were 


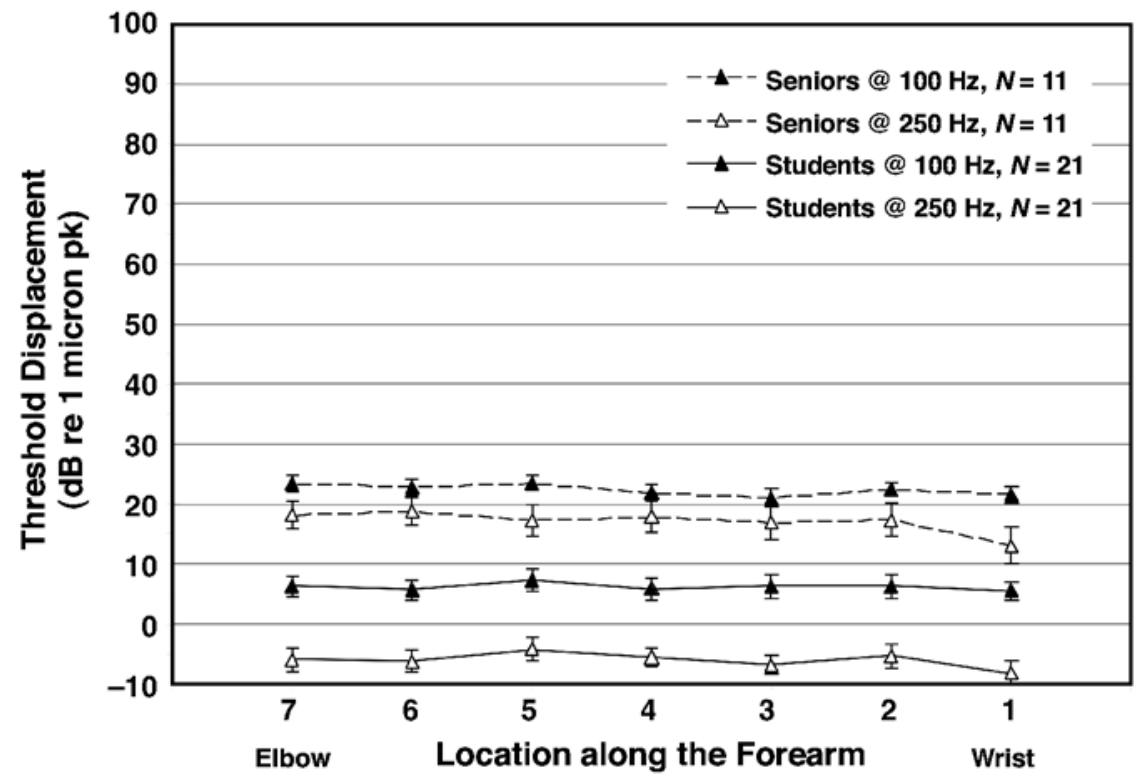

Figure 1. Vibrotactile detection thresholds, in decibels relative to 1 micron of peak displacement, are plotted for seven sites along the length of the forearm $(25 \mathrm{~mm}$ apart) from students (solid lines) and senior citizens (dashed lines). Thresholds were measured for two frequencies, 100 and $250 \mathrm{~Hz}$. (Standard errors of the means are shown on the data points.)

stimulated with a linear array of custom-designed tactors, shown in Figure 2 . The tactors were constructed from serial-connection, $0.05 \times 19 \mathrm{~mm}$ wide $\times 38 \mathrm{~mm}$ long piezoceramic benders (Piezo Systems, PSI-5A). The benders were beam mounted, with sufficient mass to ensure proper driving of the skin with perpendicular movement of the contactor. The contactor area and the size of the surround were identical to those in the threshold measurements just described: The vibrators stimulated the skin with 7-mm contactors, protruding $0.5 \mathrm{~mm}$ past a static surface, to ensure firm contact with the skin, through a 9-mm-diameter opening that created a 1-mm gap (see Gescheider et al., 1978; Verrillo, 1966, Figure 4). Because of the width of the benders and the size of the enclosures, there was a minimum of $25 \mathrm{~mm}$ between the contactors. To control the interface between the arm and the tactors, each box was covered with a
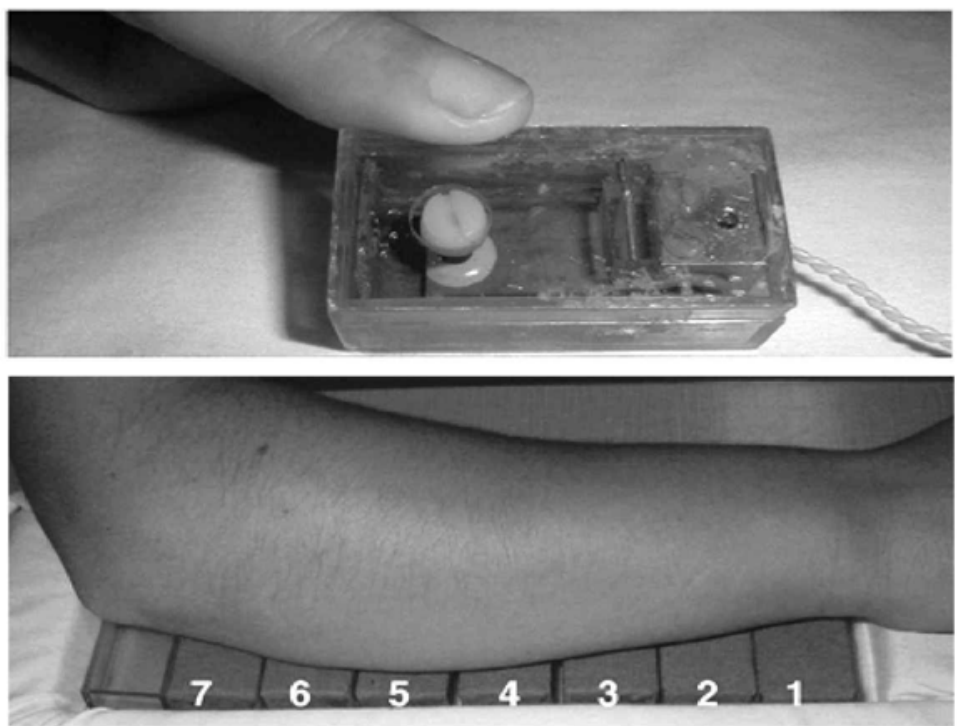

Figure 2. One of the piezoceramic tactors is shown in the upper panel, without its fabric cover. The enclosure is $25 \mathrm{~mm}$ wide, and the $7-\mathrm{mm}$ diameter moving contactor protrudes through a 9-mm diameter hole in the static surround. Seven of these are used in the tactile array, as is shown in the lower panel. 
$100 \%$ cotton knit fabric (Hanes "Beefy-T" shirt material). These tactors could be driven with a relatively broad band of frequencies, although they had less power than the shaker that was used to obtain the thresholds, shown in the previous figure. Nevertheless, they were readily able to produce the $200-\mathrm{msec} 14-\mathrm{dB}$ SL bursts of vibration used in the rest of the experiments. The timing of stimuli presented by these tactors was controlled by a computer that gated the sinusoidal output of an Exact 626 Function Generator with an IEEE-488 interface. The program-controlled function generators could vary stimulus intensity over a $60-\mathrm{dB}$ range, as well as frequency, on a trial-by-trial basis. The signals from the function generators were passed through impedance-matched Piezo Systems EPA-104 amplifiers to drive the tactors themselves through a bank of relays.

For clarity, throughout the rest of the article, the points along the forearm that are potential sites of stimulation will be referred to as locations or sites. When the location of a vibrator in the linear array is discussed, its position will be referred to by the tactor number, as is shown in Figure 2.

\section{EXPERIMENT 1 Localization on the Volar Forearm, With a Dense Array}

\section{Procedure}

In the first experiment, we explored localization accuracy for single identical bursts of vibration presented on the forearm, with seven piezoceramic tactors, described above, placed as close together as possible. Two different stimulus frequencies were tested, 100 and $250 \mathrm{~Hz}$, because there are suggestions in the literature that Pacinian receptors (most sensitive to $250 \mathrm{~Hz}$ ) have poorer spatial acuity than do non-Pacinian structures (sensitive to lower frequencies of vibration; Johnson \& Lamb, 1981; Phillips et al., 1992; Sherrick et al., 1990). Limitations in the bandwidth of the tactors prevented exploration at frequencies lower than $100 \mathrm{~Hz}$. The forearm was aligned on the array, with the most distal stimulus (Tactor 1) at an index point marked with henna dye $25 \mathrm{~mm}$ proximal to the wrist (Site 1). The dye, which can last for 2 or more weeks, allowed us to return to the same reference point on the skin from session to session, to ensure repeatable positioning of the array. Small sandbags stabilized the arm, while headphones and sound-attenuating foam reduced the effects of distracting sounds from the array or environment.

Prior to testing, a perceptual threshold for the array was measured by a descending method of limits so as to allow approximate equation of sensation magnitudes for the two stimulus frequencies. To accomplish this, the subjects were presented with a pattern of stimuli consisting of sequential bursts of vibration on each tactor in the array and were required to indicate whether all seven sites were felt. Over successive sequences, the burst intensities were reduced by $1 \mathrm{~dB}$. When the stimulus intensity fell to the point at which the activity of any one tactor could not be felt, that level was taken as threshold for the array, and the overall intensity for all seven tactors was raised by $14 \mathrm{~dB}$. Because of the punctate nature of the skin and the broad range of tissues covered by the array, it was felt that subtle differences in apparent magnitude might still exist from site to site and could provide cues to location on the basis of differences in vibrotactile loudness, rather than locus. Consequently, to remove this alternative from the repertoire of potential cues to location, over trials the intensity of the burst of vibration was randomly increased or decreased by as much as $3 \mathrm{~dB}$ around the 14-dB baseline (so the intensity ranged from 11 to $17 \mathrm{~dB}$ above the array threshold). Such an intensitive variation should not influence localization per se (Craig, 1989). To further ensure against tactor-related local cues, the individual stimulators were randomly assigned to different sites in the array on a daily basis.

Following these preliminary intensity measures, the experiment began. The subjects were required to identify the absolute locations along the forearm of each burst on an isomorphic linear seven-button keyboard. Stimulus presentation was self-paced, with a 700-msec preparatory delay preceding the burst of vibration at one randomly selected site. Feedback was provided on the visual display by showing the number of the correct location, as well as in the form of an acoustic tone. Each session consisted of five blocks of 70 trials, or 50 samples of the seven tokens, and took approximately $45 \mathrm{~min}$ to complete. Each observer served in four sessions, two at each stimulus frequency. Performance was measured in the form of the percentage of correct localizations at each site, and the form of the error functions was examined. Although only the data from the second session will be shown, a preliminary study of learning with 7 senior observers indicated that there was no meaningful increase in performance over the course of five sessions. [Although a statistically significant improvement was seen when the results of the second session were compared with the results of the fifth- $F(1,6)=$ $8.016, p<.05$ - the difference in overall performance was minimal, resulting from only a $2 \%-3 \%$ improvement per session.]

\section{Results and Discussion}

There were no significant effects of the order in which the frequencies were tested. The data from this experiment for the students and for the senior citizens are shown in Figures 3 and 4, respectively. The thresholds on the arm from Figure 1 are reproduced in Figure 3, along with the localization performance for 29 students (mean age $=24$ years, ranging from 18 to 33 years old) from the second session of 350 localization trials. Similarly, Figure 4 presents the localization performance and thresholds for 29 senior citizens (mean age $=73$ years, ranging from 60 to 85 years old). Localization performance is referred to the left ordinate and thresholds to the right. First, note the remarkable differences in localization performance over the length of the arm: The sites stimulated by the tactors at the two ends of the array were identified with an accuracy of better than $65 \%$, whereas stimulation of sites in the middle of the array led to a precipitous fall in performance to $30 \%$ or $40 \%$, depending on the age group. In all cases, however, these values are well above the $14 \%$ chance performance level for seven alternatives. Second, age did play an important role, in that overall performance was better in the younger population $[F(1,56)=8.879, p<.01]$, although note that this difference was primarily owing to the differences in localizing stimuli that occurred in the middle of the array. Students and senior citizens performed at virtually identical levels for stimuli at the ends of the array (students, $74 \%$ and $72 \%$, as compared with seniors, $71 \%$ and $68 \%$, for $250-$ and $100-\mathrm{Hz}$ stimuli, respectively). Third, note that localization was unrelated to detection sensitivity. Over a region of skin in which vibrotactile sensitivity showed no systematic variation, localization was dramatically affected by the place of stimulation $[F(6,336)=$ $96.674, p<.01]$. Finally, note that there was no significant main effect of frequency for either age group. There was a significant but negligible interaction: Frequency had a small effect on performance for the students, who localized stimuli at the ends of the array better when they were presented at $250 \mathrm{~Hz}$ than when they were presented at $100 \mathrm{~Hz}[F(6,162)=2.711, p<.05]$.

We also performed analyses of static information transfer, calculated from the stimulus/response confusion ma- 


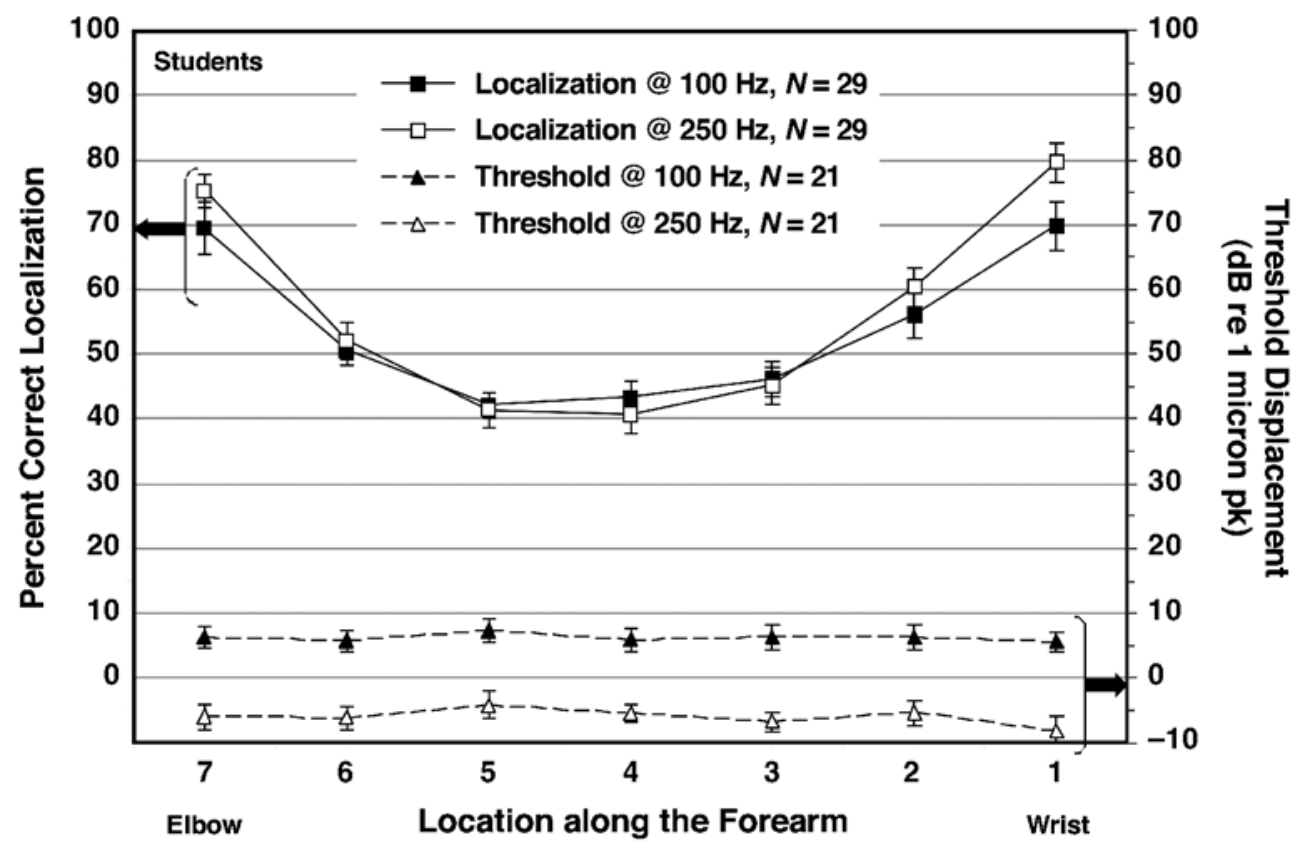

Figure 3. Vibrotactile localization performance for the students in Experiment 1 is plotted as a function of the stimulus location on the forearm (solid lines). The lower two functions (dashed lines) reproduce their vibrotactile threshold performance from Figure 1 (referred to the right ordinate) over the seven sites. The parameter is the frequency of stimulation, and the sites were $25 \mathrm{~mm}$ apart. (Standard errors of the means are shown on all data points.)

trixes (Senders, 1958). In this somewhat technical context, the amount of "information" is a function of the number of possible alternatives available to the observer. However, because the observer might not be able to appreciate all of the possible alternatives (e.g., in this case, stimuli delivered by the tactors in the middle of the array), the information transmitted (sometimes called uncertainty reduction) can be less than was originally available in the stimulus array. Miller (1956) notes that information transmitted describes the correlation between the amount of information in the stimuli and the amount in the observer's responses. In this context, the amount of information is measured in terms of bits, calculated as the logarithm (to the base 2) of the number of alternatives. In Experiment 1, with seven alternatives, 2.81 bits of information were potentially available to the observer in the stimulus array $\left(7=2^{2.81}\right)$. The analysis of the students' data over the two stimulus frequencies resulted in an average of 1.28 bits of information transferred out of the possible 2.81 bits. This value corresponds to 2.45 tokens, suggesting that an array that was one third as dense might result in nearly perfect localization performance, which would be an appropriate goal for most tactile display systems. The seniors averaged slightly poorer ( 1.05 bits, or about 2 tokens). It has been found that absolute judgments of nonvisual unidimensional stimuli asymptote near a level of about 2.5 bits (slightly less than six likely alternatives), defining the channel capacity of the observer for absolute judgments of the stimulus dimension being tested (Miller, 1956). Even when multidimensional tactile displays are tested, this rate is rarely exceeded (e.g., Rabinowitz, Houtsma, Durlach, \& Delhorne, 1987; Sherrick, 1985; Tan, Durlach, Reed, \& Rabinowitz, 1999).

In summary, these data argue that, except for stimuli presented by tactors close to the ends of the array, one cannot uniquely identify the location of a single vibrating point on the forearm when it is in an array of other sites separated from one another by $25 \mathrm{~mm}$. How do these results relate to the classical measures? Recall that, for the reasons outlined in the introduction, threshold data from classical studies of two-point discrimination or point localization for touch are likely to be inaccurate reflections of the spatial resolution for vibrotactile stimuli. Nevertheless, because so many others have made this comparison, we can make the following observations. Weinstein (1968) measured point localization thresholds (asking the question, Is this the same point that was just touched?) for males and females on the middle of the volar forearm and found them to range from 9 to $10 \mathrm{~mm}$. Similarly, two-point discrimination thresholds (asking the question, Do you feel one or two points?) on the same site ranged from 38 to $40 \mathrm{~mm}$ (identical to that measured by Weber, 1826/1978, p. 37). The paradigm in the present experiment was most comparable to that used for point localization, so one could say that by vibrating a point, the minimum separation between loci necessary to absolutely localize a particular point increases from $10 \mathrm{~mm}$ to some value greater than 


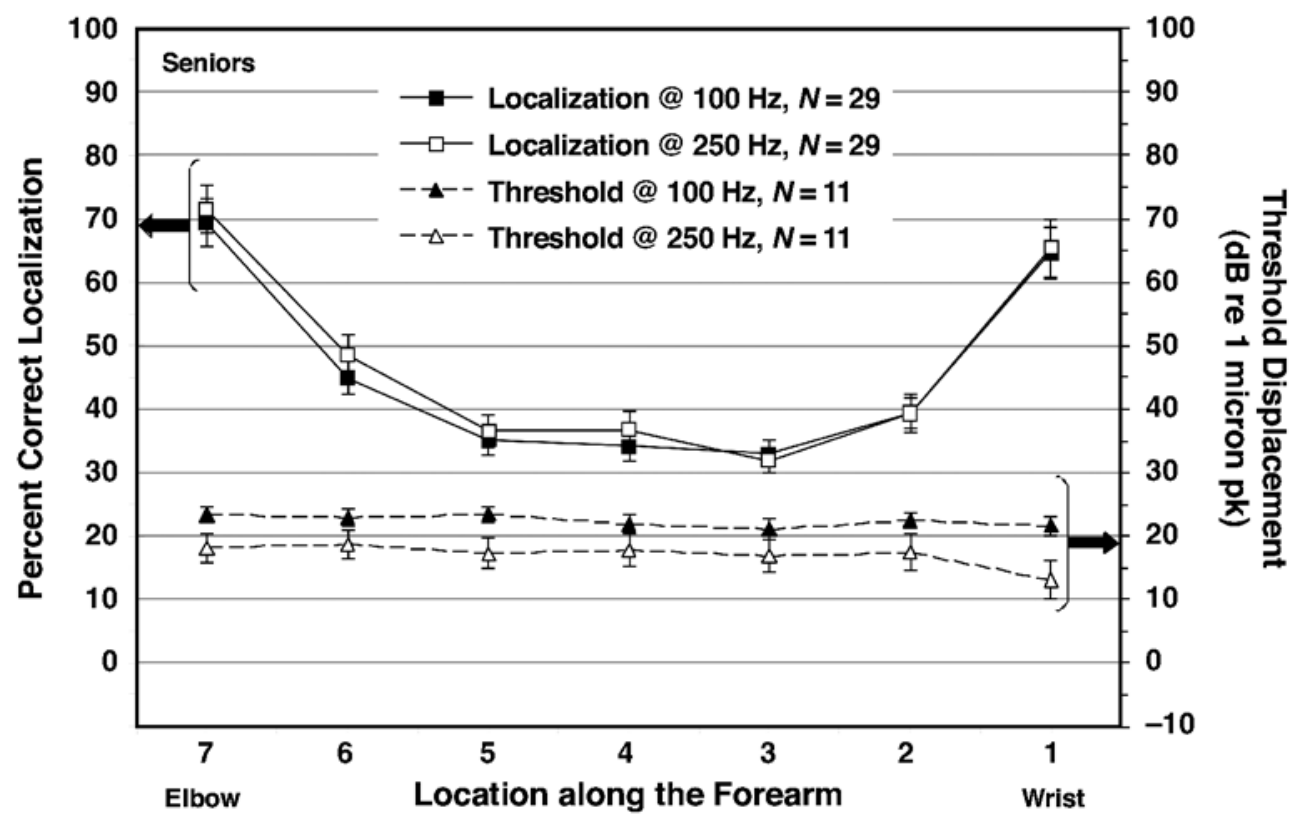

Figure 4. Vibrotactile localization performance for the senior citizen subjects in Experiment 1 is plotted as a function of the stimulus location on the forearm (solid lines). The lower two functions (dashed lines) reproduce their vibrotactile threshold performance from Figure 1 (referred to the right ordinate) over the seven sites. The parameter is the frequency of stimulation, and the sites were $25 \mathrm{~mm}$ apart. (Standard errors of the means are shown on all data points.)

$25 \mathrm{~mm}$. In a later experiment in the present series, the change in performance as the separation between potentially active vibrating sites is increased was explored.

The overall pattern of performance for the seniors was very similar to that for the students, although the levels were generally lower. From the point of view of the underlying anatomical differences between young and older skin, described earlier, one might have expected larger differences. At least two groups of receptors age dramatically over the span of years tested: the Pacinian corpuscles that are responsible for high-frequency sensitivity and Meissner corpuscles. Pacinians become fewer in number, and the remaining ones appear to atrophy. Similarly, Meissner corpuscles start to change within 10 years of birth, falling in number and diminishing in size with age (Cauna, 1965). What might be expected of these changes? First of all, detection sensitivity should be reduced, as was found in the preliminary measurements shown in Figure 1. And localization should be poorer at higher stimulus frequencies, because the neural structures that encode those stimuli have very large receptive fields. But why is localization so (relatively) good at these frequencies, and in senior citizens? Sherrick et al. (1990) found that localization of high-frequency stimuli, although slightly inferior to that with lowfrequency stimuli, was well above the expected chance levels. They hypothesized that cortical triangulation among driven receptors allowed for accurate localization, even though the receptive fields of any individual one might preclude the same level of accuracy. As a person ages, the same mechanism could be available despite the reduced numbers of receptors available to appreciate a stimulus. Furthermore, localization might not deteriorate with age, because a loss of receptors could produce less "noise" in the system since there might be fewer receptors responding to the stimulus. In the same way that it compensates for other losses by reorganizing and taking greater advantage of the remaining information sources, the central nervous system still could compare inputs among the available receptors to locate the stimulus site.

The profile of the U-shaped localization functions may appear surprising. Yet when Weber (1826/1978) discussed spatial localization on the body more than 170 years ago, he noted that localization should be more precise when the stimulus was close to some anatomical point of reference, a local sign that could provide a perceptual anchor that the observer could use in identifying the site of stimulation. He called these Anhaltspunkte (translated as regions of anchorage according to Boring, 1942, p. 486), and later work seemed to relate these to points of mobility - the joints of the body. In fact, as was mentioned earlier, Vierordt (1870) even constructed a so-called "law of mobility" stating as much. The wrist and elbow are primary examples of his points of mobility, and in agreement with these notions, localization in the present data was found to be a function of proximity to these two major joints of the arm. The closer a stimulus was to either 
anatomical landmark, the better absolute localization performance was. Hamburger (1980), explored a number of stimulus and observer variables and also found that localization was poorest for sites in the middle of the forearm, for men and women, dorsal and volar sites, left or right arms, and sharp (pinprick) or dull (toothpick) pressures.

The direction in which mislocalization occurs is also of some interest. Specifically, if this notion is correct, errors in identification of the site of a stimulus should be more likely to occur in a direction predicted by the closest reference point. Boring (1942, p. 486) cited data from Lewy (1895) and Parrish (1897), who described a strong bias in localization such that errors tended to occur in a distal direction, so that even stimulation of loci in the middle of the forearm, such as Site 4 in Experiment 1, were mislocalized toward the wrist. More recently, Hölzl, Stolle, and Kleinböhl (2002) described mislocalizations of eight individual sites in a more dense array centered on the forearm, with tactors covering only a $105-\mathrm{mm}$ extent. Using a pointing response, subjects uniformly indicated locations that were more proximal than the veridical sites, in a direction opposite to that in the work cited by Boring. All of these studies were conducted with taps or pressure pulses, rather than with the durative vibrotactile stimuli used in the present work. Nevertheless, a comparison is warranted. Analyses of response errors in the present experiment illustrated the fact that for the midpoint locus (Site 4), errors were skewed somewhat toward the elbow.

But there is another explanation for the pattern of responses seen here. Performance may have been enhanced at these outlier loci because of the increased likelihood of generating the correct response at the endpoints of the array. After all, there were fewer available alternatives when Tactors 1 or 2 (or 6 or 7) were driven. Similar points that disambiguate sensations near the ends of ranges of stimuli have been described in the literature for other sensory modalities. These have been referred to as perceptual anchors. For example, Braida and his colleagues (Braida et al., 1984) discussed the encoding of acoustic stimuli in terms of their distance from internal references (perceptual anchors). Their model posits (and the data support) the notion that acoustic stimuli that vary in intensity will be better identified when they occur near the endpoints of the range tested. Similarly, curves reminiscent of those in Experiment 1 characterize the recall of a set of pitch sequences (Deutsch, 1980), with endpoint effects leading to improved performance for those stimuli as well. This issue was explored en passant in Experiment 2.

\section{EXPERIMENT 2 \\ Localization on the Arm Crossing the Elbow With a Dense Array}

If the joints serve as important anatomical landmarks against which unknown loci might be referred and localized, what would happen if the array was placed across one of them? In this case, one might expect that the best performance would occur for the sites stimulated by tactors in the middle of the array falling on either side of the joint, whereas localization for sites farther away to either side would be poorer. In particular, the heightened localizability evident in performance at the first and last sites should disappear, since the endpoint tactors now stimulate loci in the middle of the limb. However, the relative performance for stimuli presented by specific tactors should not differ from that seen in Figures 3 and 4 if the superior performance was owing to endpoint enhancement caused by the decrease in response alternatives for sites at or near the ends of the linear array. So the second issue explored in this experiment concerned the likelihood that performance at Tactors 1 and 7 might still be enhanced because of the statistical superiority resulting from their being at the endpoints of the array. Under this scenario, localization performance for the first and last tactors would be better than that for the tactors in the middle of the array, because of the fewer response alternatives available to the observer.

\section{Procedure}

For this experiment, the elbow was placed in the middle of the array, such that Tactors 1 (the most distal) through 4 (the midpoint in the array) fell on the volar forearm, whereas Tactors 5-7 (the most proximal) contacted the upper arm. Individual sites were spaced $25 \mathrm{~mm}$ apart, which was the same separation as that used in Experiment 1. Sites falling on the upper arm were numbered 8, 9, and 10 , following the sequence started on the lower arm. Consequently, the seven tactors in Experiment 2 contacted Sites 4-10 along the lower and upper arm. Because of the construction of the tactor enclosures, it was possible to attach them (with Velcro tape) to an elastic neoprene wrap that maintained the tactors in the proper position and with a firm contact around the upper arm. Other than changing the overall location of the array on the arm, the procedures were identical to those used in the previous experiment: Both college-aged students and senior citizens were tested, with stimulus frequencies of 100 and $250 \mathrm{~Hz}$.

\section{Results and Discussion}

Data were collected from 10 college-age persons (mean age $=22$ years, ranging from 18 to 33 years old) and 13 senior citizens (mean age $=75$ years, ranging from 60 to 83 years old). All the subjects also were tested in Experiment 1, either before or after their participation in Experiment 2. Experience in Experiment 1 improved performance in Experiment 2 only for the seniors $[F(1,11)=8.506, p<.05]$. As in Experiment 1 , there was no main effect of frequency (and no significant interactions), so the following discussion will reflect performance data collapsed over the two tested stimulus frequencies. The localization data are shown in Figures 5 and 6 for the students and the seniors. The results show the strong influence of the presence of the elbow joint on vibrotactile spatial localization. Stimuli presented by Tactors 4 and 5, in the middle of the array, now falling on both sides of the joint, were much better localized by both age groups than they were when they touched the middle of the forearm in Experiment 1 [for students, 


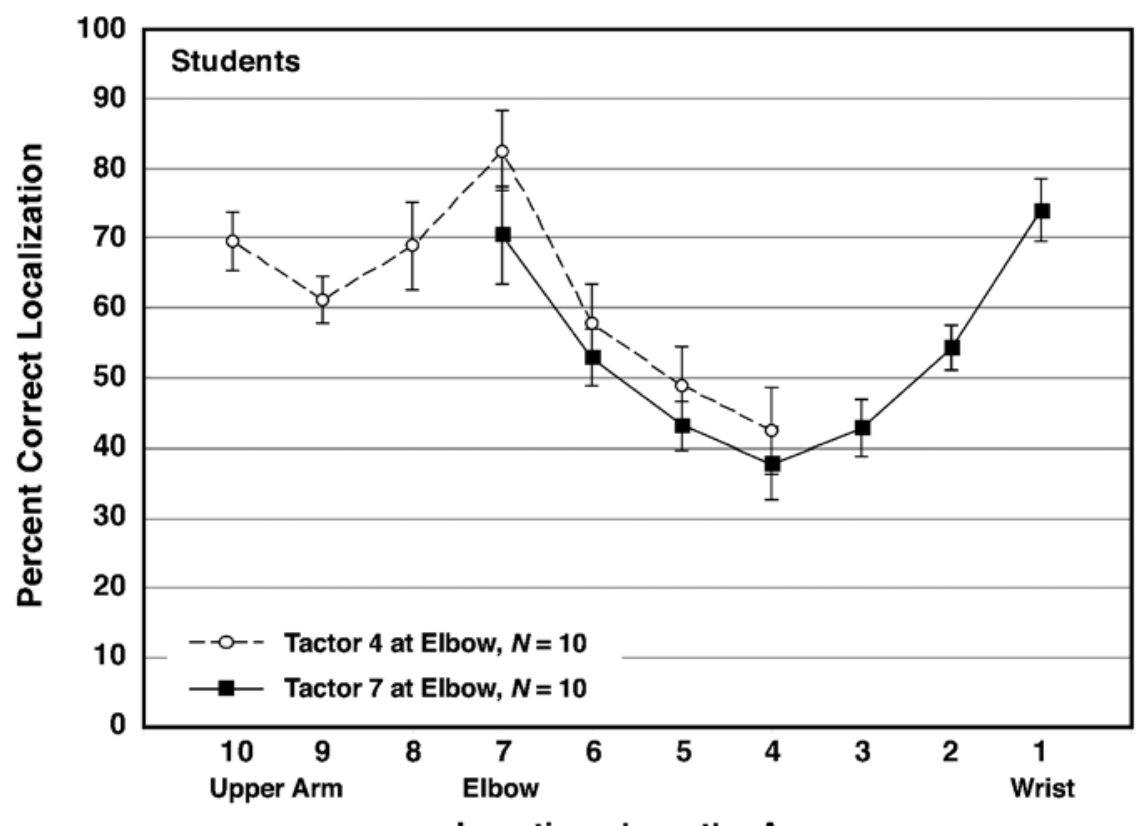

Figure 5. Vibrotactile localization performance from the students in Experiment 2 (dashed line), collapsed over frequency, are plotted as a function of stimulus location on the arm when the middle of the array was located at the elbow and the tactors were $25 \mathrm{~mm}$ apart. The data from Experiment 1 for the same group, when the array endpoint was placed near the elbow, are also plotted for comparison (solid lines). (Standard errors of the means are shown on all data points.)

Tactor $4, t(9)=9.173, p<.01 ;$ Tactor $5, t(9)=5.268, p<$ .01 ; for seniors, Tactor $4, t(12)=6.919, p<.01$; Tactor 5 , $t(12)=4.931, p<.01]$. In addition, the improvement in localization for stimulation by Tactor 1 when it was placed near the wrist in the "standard" condition of Experiment 1 was lost, and performance dropped for that tactor, which now fell in the middle of the arm [for students, Tactor $1, t(9)=6.457, p<.01$; for seniors, Tactor 1 , $t(12)=4.743, p<.01$, and Tactor $2, t(12)=2.216, p<.05]$.

Indeed, when performance between Experiments 1 and 2 is compared directly by location on the arm, no significant difference was found at Site 7 for either age group, as is obvious by an examination of Figures 3 and 4 . The findings support the notion that place (where one stimulates the skin) plays a powerful role in vibrotactile localization.

Interestingly, again the effect of age appears to be most pronounced for the most distal sites: Performance at the array midpoint, Site 4, and proximal Sites 7-10 was about the same for the two age groups, whereas distal Sites 5 and 6 were comparatively less well localized by the seniors. Also note that the general shape of the function over the sites distal to the elbow is hardly changed from before. For those points proximal to the elbow, present only in Experiment 2 , however, performance was very good-perhaps because there were only three sites and two of them were close to either elbow or shoulder joints. The overall increase in performance resulting from the improvement at these sites is reflected in the analysis of overall information transfer. There was a distinct reduction in uncertainty: For the students and seniors, static information transfer, collapsed over stimulus frequency, increased to an average of 1.67 bits (3.18 tokens) and 1.43 bits (2.69 tokens), respectively. In summary, these data support the notion that the place on the body that is stimulated, and not merely the location on an array, plays a powerful role in vibrotactile localization. But there is a limited number of loci on the body that can be used as such points of reference. In the next experiment, we explored the possibility of creating artificial anchor points, serving the same referent function as the natural ones represented by the joints.

\section{EXPERIMENT 3 \\ Localization on the Volar Forearm, With a Dense Nonhomogeneous Array}

\section{Procedure}

In this experiment, the spatial conditions from Experiment 1 were used, in which the seven sites were close together (25-mm separation) on the lower volar forearm. As before, sessions in which either $100-$ or $250-\mathrm{Hz}$ bursts of stimuli were presented on each site were tested, with the exception that whenever Site 4 was presented, it was driven with the frequency opposite to that used for the other loci. That meant that there was an odd site, one that was qualitatively different from the others in the array. On the basis of Goff's (1967) data on differential discrimination of frequency, a $250-\mathrm{Hz}$ suprathreshold 


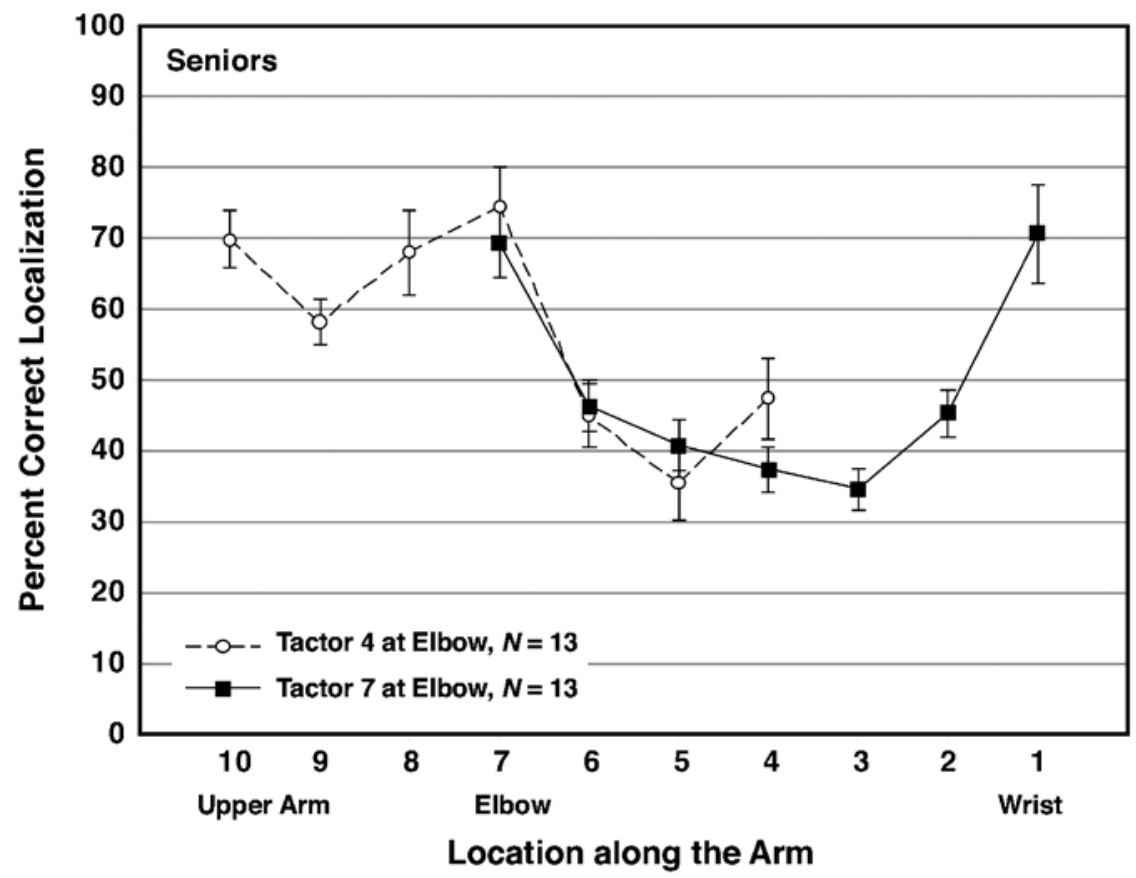

Figure 6. Vibrotactile localization performance from the Experiment 2 seniors (dashed line), collapsed over frequency, are plotted as a function of the stimulus location on the arm when the middle of the array was located at the elbow and the tactors were $25 \mathrm{~mm}$ apart. The data for the same group from Experiment 1, in which the array endpoint was placed near the elbow (solid line), are also plotted for comparison. (Standard errors of the means are shown on all data points.)

stimulus is two to three just-noticeable-difference steps above a $100-\mathrm{Hz}$ stimulus, so the odd site should be distinguishable from the rest, standing out from its neighbors. We chose Site 4 in the center of the forearm, because it proved to be one of the most difficult sites to localize. The protocol was identical to that described for the previous experiments. When thresholds were measured initially, the stimulus frequency presented to all of the sites was the baseline frequency for that session. Thus, in a session in which $250 \mathrm{~Hz}$ was the stimulus frequency for Sites $1-3$ and 5-7, Site 4 was also driven with $250 \mathrm{~Hz}$ during the threshold measurement, even though, during the test phase, it would be driven with a $100-\mathrm{Hz}$ sinusoid. The consequences of this protocol were that the perceived test intensity at Site 4 would differ from that at the other sites, by virtue of the differences in sensitivity between 100 and $250 \mathrm{~Hz}$, and that the stimulus intensity for all sites was raised to $14 \mathrm{~dB}$ above the baseline level. This was deemed advantageous because the intent was to make Site 4 feel different from the rest of the sites. The localization task itself was identical to that used above, and the observers were not informed about the presence of the odd site.

\section{Results and Discussion}

Data were collected from 9 college-age persons (mean age $=22$ years, ranging from 18 to 33 years old) and 13 senior citizens (mean age $=73$ years, ranging from 60 to 83 years old) and are shown in Figures 7 and 8 for the students and the seniors, respectively. All the subjects also were tested in Experiment 1, either before or after their participation in Experiment 3, and these figures directly compare their performances under the two condi- tions. For the senior observers, performance was better for the second of the two tasks, regardless of which task was first $[F(1,11)=21.584, p<.01]$. There was a significant main effect of age group, with student performance superior to that of the seniors $[F(1,20)=8.224$, $p<.01]$. As was expected, there was a significant main effect of the location of stimulus on the array $[F(6,120)=$ $27.897, p<.01]$ : Performance tended to be better for the stimuli presented by tactors at the ends of the array. But what about the performance for the odd site? There was an interesting interaction between age and stimulus frequency. The results in the figures show that for the student population, there was a larger effect of this subtle manipulation when the majority of the array was driven at one of the frequencies while Tactor 4 was driven at the other $[F(6,42)=3.485, p<.05]$. This result was larger for the condition in which Tactor 4 was at $250 \mathrm{~Hz}$ and the others were at $100 \mathrm{~Hz}[t(8)=2.724, p<.01]$. Because the calculation of information transfer takes into account both correct responses and response biases, the overall results are not as dramatically different: When the odd tactor was driven at $100 \mathrm{~Hz}$, information transfer was 1.45 bits (2.73 tokens), whereas for $250-\mathrm{Hz}$ stimuli at that site, 1.38 bits were transferred ( 2.60 tokens). The data from the senior citizens showed similar but less remarkable results. There was a significant interaction between frequency and task in this population $[F(1,11)=$ 


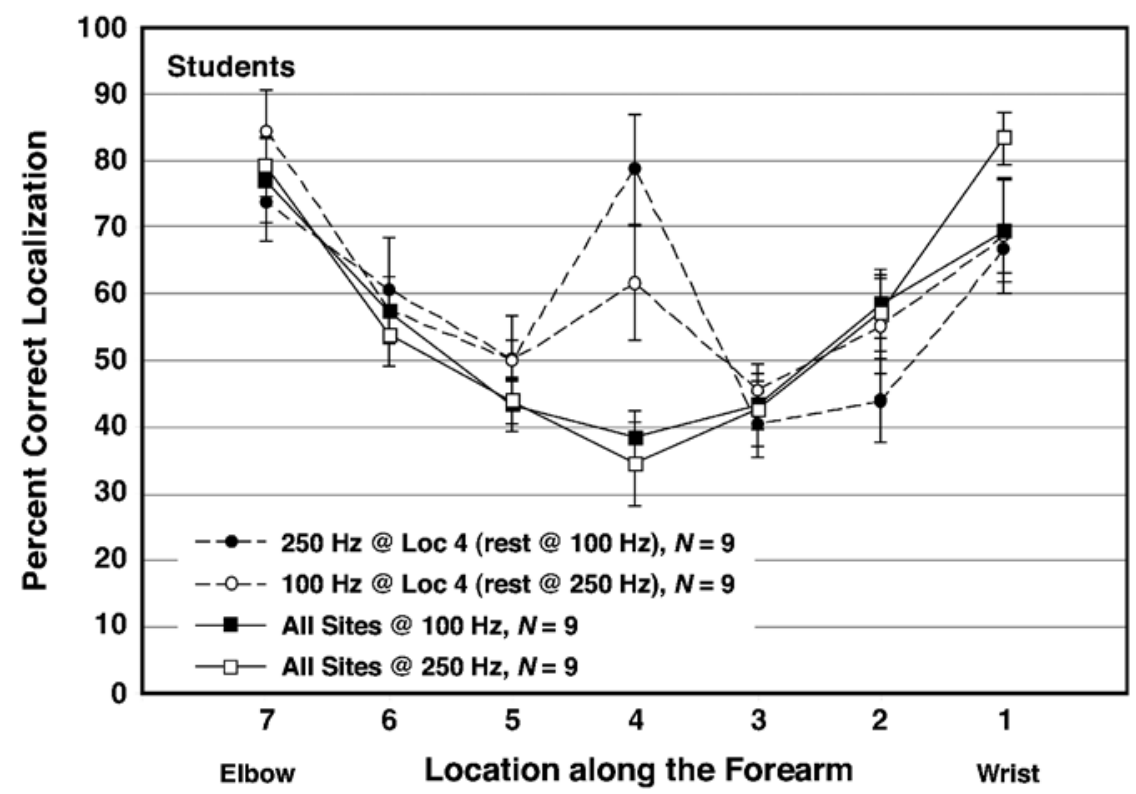

Figure 7. Vibrotactile localization for the students in Experiment 3 (dashed lines) are plotted along with their performance from Experiment 1 (solid lines) as a function of stimulus location when the middle tactor in the array was driven with a stimulus frequency different from that used on the remainder of the vibrators. When the majority of the array was driven with $100 \mathrm{~Hz}$, Site 4 was driven with $250 \mathrm{~Hz}$, and vice versa. The parameter is frequency of stimulation. (Standard errors of the means are shown on all data points.)

$5.049, p<.05]$, in that a difference in performance between the results of Experiment 3 and Experiment 1 was present only when the $250-\mathrm{Hz}$ stimulus was presented at Site 4. Although Site 4 performance in this condition was significantly better than that at Sites 3 and 5, it was not statistically superior to Site 4 performance at either frequency in Experiment 1. Overall, information transfer for the seniors was only slightly improved when compared against that from Experiment 1 (increasing to 1.12 bits, or 2.17 tokens). The less-than-definitive effect of the manipulations of Experiment 3 may be related to the fact that none of the observers was told that activity at Site 4 would differ in quality from that at the rest of the sites but, rather, was left to discover it by him- or herself. The intention was to mimic testing in the original condition, in which the subjects had to discover the utility of the wrist and elbow references on their own. It is notable that senior performances at Sites 3, 4, and 5 were not significantly different from one another in Experiment 1, so the effect of changing the quality of the Site 4 target seems to have increased the contrast of that site, relative to its neighbors.

The case of the students tested when the majority of the array was driven at $100 \mathrm{~Hz}$, however, requires an explanation that, although complicated, is consistent with the test conditions. Part of the answer to the superiority of Site 4 in the condition in which it was presented to students at $250 \mathrm{~Hz}$ comes from addressing the question of why there was such a small effect with the seniors. The threshold curves in Figure 1 show that sensitivity on the arms of seniors was very similar for the two stimulus frequencies. Consequently, when stimulus frequencies were mixed in this experiment, the apparent magnitudes of the suprathreshold stimuli were similar (since these two frequencies have comparable growths-of-loudness functions; Verrillo, Fraioli, \& Smith, 1969), leaving only frequency and locus as the bases for distinguishing Site 4 from the remaining sites. Since in Experiments 1 and 2 locus alone had been proven to be a poor discriminandum when it fell in the middle of the forearm, identification of the stimuli could have been based on frequency alone, and this seems not to have provided for a strong qualitative distinction. In the case of the students, however, the comparatively large difference in threshold sensitivity translated into a similarly large difference in perceived magnitude between the two frequencies, particularly when the overall intensity of the array was based on $100-\mathrm{Hz}$ thresholds. In this case, the $250-\mathrm{Hz}$ Site 4 was felt to be quite strong (adding the 14-dB re $100-\mathrm{Hz}$ threshold to the $14-\mathrm{dB}$ difference in thresholds $=$ $28-\mathrm{dB}$ re $250-\mathrm{Hz}$ threshold). On the other hand, when the situation was reversed, the $100-\mathrm{Hz}$ Site 4 was very quiet, relative to the remaining sites, providing a less distinctive cue that resulted in a less impressive improvement in performance.

So it appears to be possible to add another place to the body to use as a referent for vibrotactile localization, but in order for it to be as useful as the joints are, it probably should be much more distinctive than most of the ones tested here. But what about space? It should also be pos- 


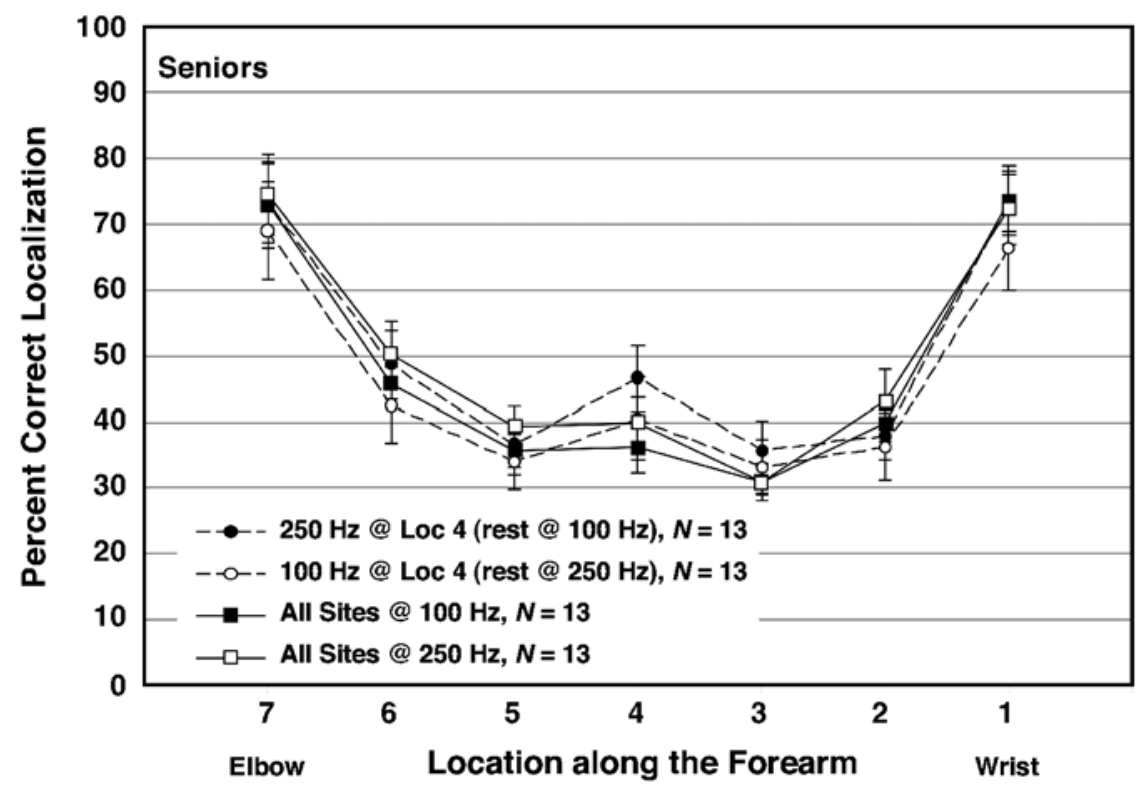

Figure 8. Vibrotactile localization performance is plotted as a function of stimulus location for the senior citizens in Experiment 3 (dashed lines), along with their performance from Experiment 1 (solid lines). The dashed-line functions were obtained when the tactor in the middle of the array was driven with a stimulus frequency that differed from that on the remainder of the vibrators and contrast with the solid-line functions for the single-frequency conditions. When the majority of the array was driven with $100 \mathrm{~Hz}$, Site 4 was driven with $250 \mathrm{~Hz}$, and vice versa. The parameter is stimulus frequency. (Standard errors of the means are shown on all data points.)

sible to improve localization by reducing the confusion among adjacent sites by increasing the spatial separation between tactors. Although on the arm this raises issues with additional anchor points, in the next experiment we explored the effect of increasing the distance between tactors.

\section{EXPERIMENT 4 \\ Localization on the Arm, With an Extended Array}

\section{Procedure}

In the next experiment, the separation between adjacent tactors was doubled to $50 \mathrm{~mm}$. This meant, of course, that some of the sites had to extend beyond the elbow onto the upper arm, just as they did in Experiment 2. In this case, the first four tactor sites were distributed over the same linear extent as was the whole array in Experiment 1 . In fact, Tactors 1-4 in this extended array fell on Sites $1,3,5$, and 7 that were tested in Experiment 1 . To be consistent with the previous experiments, a number of sites on the upper arm were defined, spaced in 25-mm increments and numbered from 8 to 13 . In this experiment, Tactors 5-7 fell on Sites 9, 11, and 13. Again, as in Experiment 2, the wearable wrap system was used to maintain the contact pressure and physical separation for the three tactors in the proximal portion of the array on the upper arm. Stimulus frequency and locus were the parameters in this experiment.

\section{Results and Discussion}

Data were collected from 19 senior citizens (mean age $=$ 70 years, ranging from 60 to 83 years old) and 7 college- age persons (mean age $=22$ years, ranging from 18 to 33 years old). As in the previous experiments, there was no significant main effect of frequency, so the performance data will be collapsed over the two tested stimulus frequencies for the following discussion. The results, shown in Figures 9 and 10 for the two age groups, illustrate that, overall, performance with the extended array was very good. This is made more obvious when the results are compared directly against those from the standard condition described in Experiment 1, also plotted in the figures. Performance improved considerably when tactor separation was increased from 25 to $50 \mathrm{~mm}$ [for students, $F(1,6)=176.866, p<.01$; for seniors, $F(1,18)=$ $94.430, p<.01]$. Interestingly, the measured effect of age $[F(1,24)=7.042, p<.05]$ is larger here than it was in the other experiments: Overall, the students performed at levels occasionally as much as $20 \%$ better than the seniors, although ex tending the spacing for the seniors provided for a similar improvement, when compared against their performance with the more dense array. Nevertheless, even with this well-distributed array, performance was not perfect. Although the traditional methodology for measuring error of localization was not employed here, these data could be taken to imply that the threshold for localization of vibrating points on the forearm is somewhat greater than $50 \mathrm{~mm}$. An information transfer analysis of these data showed that, for the extended array, 2.03 bits (4.08 tokens) and 1.65 bits (3.14 tokens) of in- 


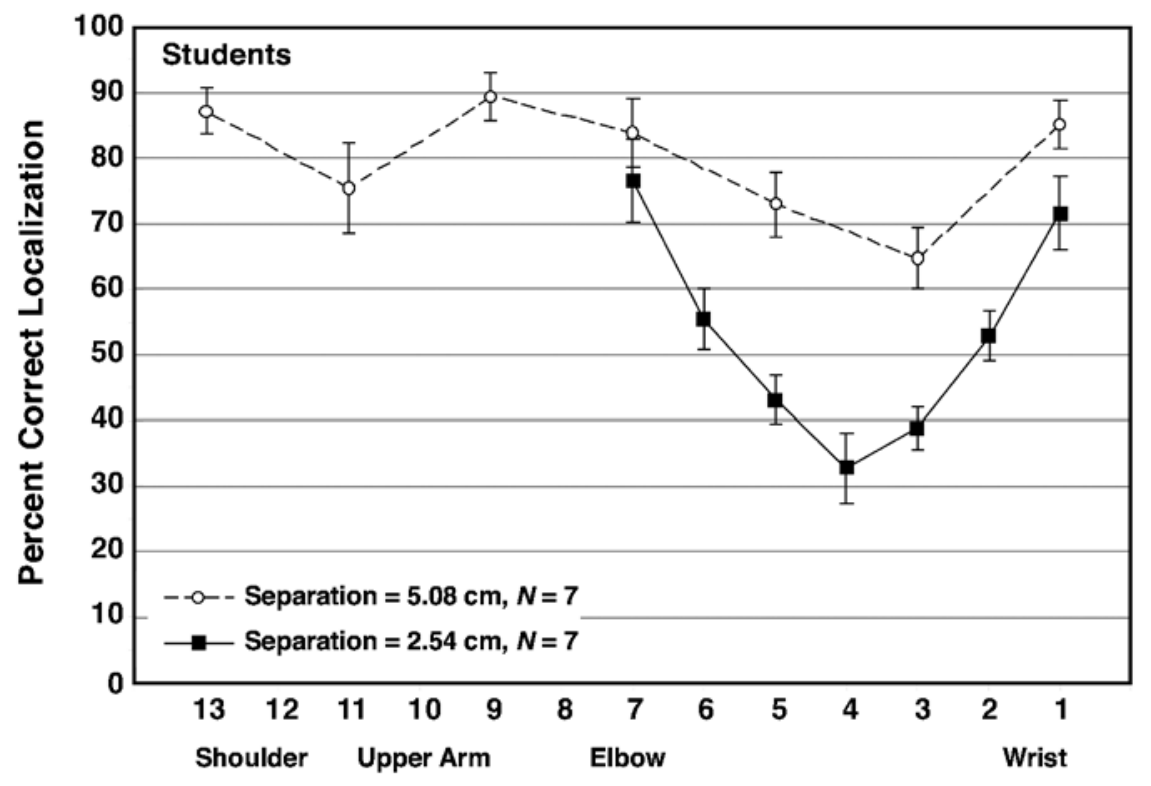

Location along the Arm

Figure 9. Vibrotactile localization performance for the students in Experiment 4 (dashed line) is plotted, collapsed over frequency, as a function of stimulus location on an extended array. Tactors, separated by $50 \mathrm{~mm}$, were distributed over the upper arm and the forearm. Performance from Experiment 1 is also plotted for these students (solid line) when the tactors were spaced $25 \mathrm{~mm}$ apart and all were positioned on the forearm. (Standard errors of the means are shown on all data points.)

formation were transmitted for the students and the seniors, respectively, reflecting the better overall percentage of correct performance by the students. These values are consistent with the one-dimensional results from Rabinowitz et al. (1987). They are, however, still well below the potential information in the seven-site array ( 2.81 bits) or even Miller's (1956) nominal 2.5-bit channel capacity for absolute judgments of unidimensional stimuli, suggesting that the channel capacity of the observers was not exceeded by the task.

Sites 1, 3, and 5 were common to the pattern sets having tactor separations of both $25 \mathrm{~mm}$ (in Experiment 1) and $50 \mathrm{~mm}$ (in Experiment 4). Localization of these three sites was statistically better in the extended condition, as compared with that in the dense condition [for students, $F(3,18)=5.038, p<.05$; for seniors, $F(3,18)=$ $6.149, p<.01]$. Thus, the greater separation among the target stimuli contributed greatly to the improvement in performance seen in the extended condition, as opposed to merely the addition of potentially more identifiable loci on the upper arm. Even so, the powerful effect of place continued to result in better performance at the sites near the joints, including the wrist (Site 1), the elbow (bracketed by Sites 7 and 8), and the shoulder (Site 13), than at those sites in between. Even with the extended array, performance at Site 3, which is in the middle of the forearm, was found to be significantly poorer than that at the majority of other sites for both the students and the seniors. Consequently, it appears that although the space between potential sites on the arm is important, as one might expect, so is the influence of place, particularly when loci fall near the joints, the arm's natural reference points.

\section{GENERAL DISCUSSION}

The intention of this project was to explore some of the parameters of vibrotactile localization. The dimensions of the most compact array used in the experiments approximated those of a commercially available tactile device used to augment speech reading by persons who are deaf. The data argue that, if absolute localization is important in a tactile code, this physical arrangement and the stimulus parameters tested should lead to poor performance. In fact, when the user is properly trained, the Tactaid-7 provides significant improvements in speech comprehension (Weisenberger, 1992). It is likely that the relevant cues in the dynamic patterns presented in speech processors such as the Tactaid-7, are positional, based on relative changes in activity as the pattern evolves and dances over the surface of the array. Other coding schemes, such as targeting, might depend more on absolute localization of activity in an array.

The first dimension that was examined in these studies was that of place, addressing the question of whether absolute localization might depend on where on the limb the 


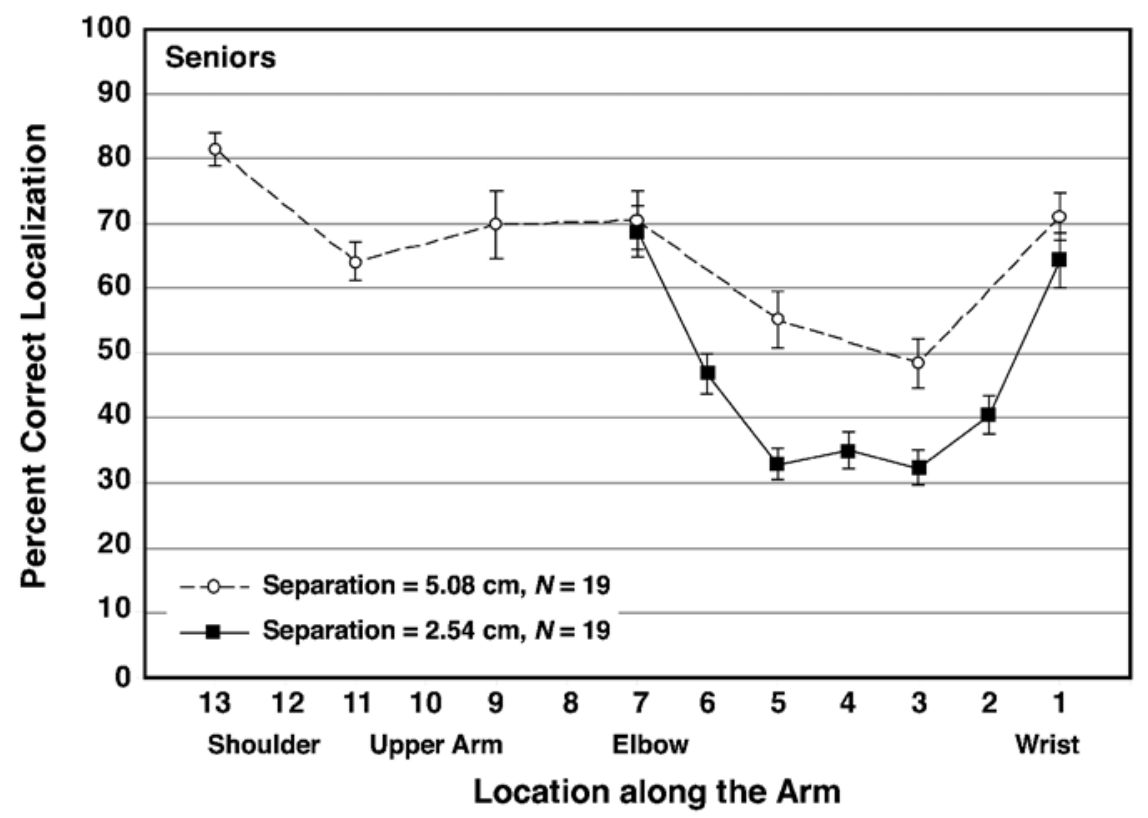

Figure 10. Vibrotactile localization performance from Experiment 4 for seniors (dashed line) is plotted, collapsed over frequency, as a function of stimulus location on an extended array. The tactors were $50 \mathrm{~mm}$ apart and were distributed over the upper arm and the forearm. Also plotted is the performance for these subjects in Experiment 1 (solid line), when the tactors were spaced $25 \mathrm{~mm}$ apart only on the forearm. (Standard errors of the means are shown on all data points.)

elements in an array are located. This proved to be an interesting problem because of the involvement of anatomical landmarks - specifically, the joints of the wrist and the elbow. As was described earlier, these regions of mobility have been regarded historically as reference points against which the observer could measure the locus of an unknown stimulus on the body's surface. Taken together, the results of Experiments 1 and 2 argue that the controlling factor in vibrotactile localization appears to be the place on the body that is stimulated by the array: If points of stimulation fall adjacent to natural anchor points, performance will be considerably enhanced at those sites, when compared against localization for sites far from such loci.

Knowing that natural anchor points exist and that they can exert an overwhelming influence on tactile localization, it was of interest to know whether it was possible to create artificial anchor points. The results of Experiment 3 suggest that including an odd site, one that had a quality different from the rest in the array, was helpful to localization (Figures 7 and 8). This ability to create artificial anchor points is an interesting and potentially useful finding. There are sites on the body, such as the abdomen or the back, where there are no obvious joints or Anhaltspunkte (regions of anchorage, Boring, 1942) and yet where certain applications may require accurate localization. One device currently under test, the Tactile Situation Awareness System, is an array that is intended to be worn on the trunk to provide a variety of information, including targeting and tracking, that could require ap- preciation of the exact location of a vibratory stimulus (Raj et al., 1998). The range and number of identifiable qualitative differences that could be used for such a purpose is probably somewhat limited. Studies of dimensional interactions, using tactile stimuli, have shown that, for a number of cutaneous communication systems, tokens defined by varying stimulus frequency, intensity, and location, do not lead to simple additive increases in information transmission (Reed \& Durlach, 1998; Sherrick, 1985; Tan et al., 1999; Taylor, 1977). It is unlikely, for example, that presenting the seven sites in this study at seven different frequencies would result in a meaningful improvement in performance. However, the potential overall effect of only a few well-placed distinctive anchors within an otherwise uniform field would be to raise performance to a significant degree, as was suggested by the influence of the natural joint reference points in the array tested. Consequently, it is likely that localization performance at specific loci in a Ganzfeld of test stimuli can be improved by references to anatomical landmarks, and artificial nonanatomical landmarks, as well as perceptual anchors provided by the endpoints of the stimulus range.

The manipulation of stimulus frequency in these experiments led to an interesting result: At least over the range of $100-250 \mathrm{~Hz}$, the effect of varying frequency was minimal. This pair of frequencies, although somewhat restricted by the response characteristics of the tactors, nevertheless should have appealed to different receptor 
populations with spatial characteristics that would have resulted in better localization for the lower frequency stimuli than for the higher. The findings that the differences were inconsequential, at least in terms of the theoretical distinctions, are complementary to those of Sherrick et al. (1990). Recall that they also showed that two stimuli appealing to PC and non-PC channels were well localized, at levels of accuracy greater than $80 \%$. Although the difference in performance between their two frequencies was statistically significant in favor of the non-PC stimuli, the absolute difference, even when the two tested sites were $10 \mathrm{~mm}$ apart on the hypothenar of the palm, was only approximately $5 \%$. Similarly, Summers and Chanter (2002) have been able to show that spatial acuity for moving stimuli presented at $320 \mathrm{~Hz}$ (in the PC range) on a dense vibrotactile array on the fingertip was actually somewhat better than it was when stimuli were presented at $40 \mathrm{~Hz}$ (a non-PC frequency).

How could the PC tactile channel, having such a huge peripheral receptive field, provide the information necessary for accurate localization? There are a number of models in the literature that might explain such acuity or discrimination in systems composed of elements that, when examined individually, should not be able to resolve the stimuli as well as they actually do. For example, Linster and colleagues (Cleland \& Linster, 2002; Linster \& Cleland, 2001) have discussed how strong odors, which evoke spatially broad glomerular patterns of activity resulting in overlapping odor representations, are nevertheless able to be well discriminated in a computational model of neuronal synchronization. Feldman and Ballard (1988, p. 16) and Erickson (1982, p. 88) also have proposed computational schemes that could account for discriminability in presumptively indiscriminate sensory systems. Whether such is the case here is a question for others to answer, but it is possible that the multiplicity of identical structures that exist in a region of skin could allow for a form of sensory triangulation. Erickson's across-fiber model of neural coding proposes that fine distinctions in quality can be made owing to the activity of a central comparator that examines the combined activity from a number of active receptors. This general model has been applied across several sensory modalities, and he argues that when broadly tuned receptors are driven by a single stimulus, the resulting population response can be more narrowly defined than it can when a population of narrowly tuned receptors are stimulated. This mechanism certainly can account for the better-thanexpected levels of performance with high-frequency stimuli. It is also possible, however, that the similarity in performance across the two frequencies could be the consequence of stimulating the same receptor populations. Although the threshold data obtained earlier indicated considerably different sensitivity when the sites were stimulated by the two frequencies, the localization test paradigm included presentation of these at equivalent baseline levels of perceived magnitude. Owing to the shapes of the frequency-response contours for the several populations of receptors (see Bolanowski et al., 1994), this could have resulted in stimulation of both PC and non-PC receptor populations, albeit at different effective levels of intensity. The likelihood of this happening is greater in the senior population than for the students, because the difference in vibratory sensitivity between the two frequencies over these sites in younger skin can be as much as $10 \mathrm{~dB}$ or more, whereas the difference for older skin is less than $3 \mathrm{~dB}$ (Figure 1). Consequently, when suprathreshold stimuli of either frequency are presented at $14 \mathrm{~dB}$ re threshold, despite the greater sensitivity of the Pacinian corpuscles, both populations are activated, and localization could be cued by the more accurate system. A greater separation in stimulus frequency and more precise control of stimulus intensity, as was done by Sherrick et al. (1990), would have to be added to this paradigm in order to evaluate this alternative.

The results from the first three experiments demonstrated that a physical separation of $25 \mathrm{~mm}$ was insufficient to provide very accurate identification of seven loci along the surface of the forearm. Without adding other anchor points, performance appears to be somewhat limited by the resolution of the skin. Another alternative for improving performance, although somewhat less desirable for a number of reasons, would be to place the vibrotactile stimuli farther apart in order for them to be well identified. This manipulation introduced the dimension of space, in order to overcome the mechanical and physiological interactions that inevitably would produce interference in vibrotactile localization. Once the seven sites were stretched from 25 to $50 \mathrm{~mm}$ apart, overall performance jumped from an average of $46 \%$ to $66 \%$, with a high of over $83 \%$ correct identifications at one of the sites in the extended condition. However, at least on the limbs, increasing space is inevitably confounded with the advantageous effects of place, since more and more natural reference points (the joints) become involved as the array covers longer and longer linear extents. Work is continuing on this issue, with finer variations in separation.

Finally, the differences in localization ability between younger and older persons were smaller than expected. The anatomical literature is quite definitive regarding the deleterious effects of aging on the number and morphology of the structures presumably involved in tactile sensitivity. For example, the density of Meissner corpuscles falls from 24 per $\mathrm{mm}^{2}$ in young people to 8 per $\mathrm{mm}^{2}$ in 70-year-old seniors (Bolton, Winkelmann, \& Dyck, 1966). Presumably, this decrease in the number of receptors, or perhaps a decrease in their functional capacity (resulting from the tortuous distortions in shape seen in both aged Pacinian corpuscles and Meissner corpuscles), leads to the changes in vibrotactile sensitivity, described in the Preliminary Measurements section, above. If the results in the localization experiments reflected the pattern of aging implied by the threshold data, the separation between the age groups that we found in localization performance (albeit for suprathreshold stimuli) should 
have been much greater. Overall, the students did localize stimuli more accurately than did the seniors (i.e., average levels of performance in Experiment 1 were $55 \%$ correct for the students and $46 \%$ correct for the seniors, including both frequencies). But like the results, described above, in our studies of localization as a function of stimulus frequency (Sherrick et al., 1990), although overall performances between the groups were significantly different, they were much more similar than what was expected. Indeed, Gescheider et al. (1996) have an extended discussion regarding the possible mechanisms that can account for their comparable findings when they examined the DL for intensitive changes in suprathreshold vibrotactile stimuli in Pacinian channels. Despite the large difference that they recorded in detection threshold between their young and older populations, as we found here, there was no significant difference between the two age groups in relative DL. Similarly, Goble et al. (1996) found comparable results, but in the spatial realm: Spatial summation was not affected by age, despite the presumed dramatic change in receptor density that occurs over the lifespan. There are a number of other situations in which pattern perception can occur in the presence of degraded conditions. Despite the visually noisy conditions experienced with precable television antenna reception or the acoustically noisy conditions often occurring in AM radio signals, perceptual processing searches out the relevant pattern to provide meaning, despite the deteriorated message. Or perhaps the loss of sensory sensitivity creates an advantage for the older skin, as for the a cappella singer: In the absence of a large surrounding group of instruments, the solitary voices come through more clearly and more well defined!

\section{REFERENCES}

Axelrod, S., \& Cohen, L. D. (1961). Senescence and embedded-figure performance in vision and touch. Perceptual \& Motor Skills, 12, 283 288.

BÉKÉSY, G. von (1960). Experiments in hearing. New York: McGrawHill.

Bolanowski, S. J., Gescheider, G. A., \& Verrillo, R. T. (1994). Hairy skin: Psychophysical channels and their physiological substrates. Somatosensory \& Motor Research, 11, 279-290.

Bolanowski, S. J., Gescheider, G. A., Verrillo, R. T., \& CheckOSKY, C. M. (1988). Four channels mediate the mechanical aspects of touch. Journal of the Acoustical Society of America, 84, 1680-1694.

Bolton, C. F., Winkelmann, R. K., \& Dyck, P. J. (1966). A quantitative study of Meissner's corpuscles in man. Neurology, 16, 1-9.

BorING, E. G. (1942). Sensation and perception in the history of experimental psychology. New York: Appleton-Century.

Braida, L. D., Lim, J. S., Berliner, J. E., Durlach, N. I., Rabinowitz, W. M., \& Purks, S. R. (1984). Intensity perception: XIII. Perceptual anchor model of context-coding. Journal of the Acoustical Society of America, 76, 722-731.

CAunA, N. (1965). The effects of aging on the receptor organs of the human dermis. In W. Montagna (Ed.), Advances in biology of skin: Aging (Vol. 6, pp. 63-96). New York: Pergamon.

Cholewiak, R. W., \& Collins, A. A. (1991). Sensory and physiological bases of touch. In M. A. Heller \& W. Schiff (Eds.), The psychology of touch (pp. 23-60). Hillsdale, NJ: Erlbaum.

Cholewiak, R. W., \& Collins, A. A. (1993). A comparison of complex vibrotactile pattern perception on the OPTACON by young and old observers [Abstract]. Journal of the Acoustical Society of America, 93, 2361 .

Cholewiak, R. W., \& Collins, A. A. (1995). Vibrotactile pattern discrimination and communality at several body sites. Perception \& Psychophysics, 57, 724-737.

Cleland, T., \& Linster, C. (2002). How synchronization properties among second-order sensory neurons can mediate sensory salience. Behavioral Neuroscience, 116, 212-221.

Coté, J. J., \& Schaefer, E. G. (1981). Perceptual processing strategies in the cross-modal transfer of form discrimination: A developmental study. Journal of Experimental Psychology, 7, 1340-1348.

CRAIG, J. C. (1989). Interference in localizing tactile stimuli. Perception \& Psychophysics, 45, 343-355.

Craig, J. C., \& Johnson, K. O. (2000). The two-point threshold: Not a measure of tactile spatial resolution. Current Directions in Psychological Science, 99, 29-32.

Craig, J. C., \& Lyle, K. B. (2002). A correction and a comment on Craig and Lyle (2001). Perception \& Psychophysics, 64, 504-506.

DeUTSCH, D. (1980). The processing of structured and unstructured tonal sequences. Perception \& Psychophysics, 28, 381-389.

ERICKSON, R. P. (1982). The across-fiber pattern theory: An organizing principle for molar neural function. In W. D. Neff (Ed.), Contributions to sensory physiology (Vol. 6, pp. 79-110). New York: Academic Press.

Eskildsen, P., Morris, A., Collins, C. C., \& Bach-Y-Rita, P. (1969). Simultaneous and successive cutaneous two-point thresholds for vibration. Psychonomic Science, 14, 146-147.

Feldman, J. A., \& Ballard, D. H. (1988). Connectionist models and their properties. In D. Waltz \& J. A. Feldman (Eds.), Connectionist models and their implications: Readings from cognitive science (pp. 13-62). Norwood, NJ: Ablex.

FoulKe, E. (1982). Reading braille. In W. Schiff \& E. Foulke (Eds.), Tactual perception: A sourcebook (pp. 168-208). Cambridge: Cambridge University Press.

Franke, E. K., von Gierke, H. E., Oestreicher, H. L., \& von WitTERN, W. W. (1951). The propagationof surface waves over the human body (USAF Tech. Rep. 6464). Dayton, OH: Wright-Patterson Air Force Base, Aero Medical Laboratory.

Frisina, R. D., \& Gescheider, G. A. (1977). Comparison of child and adult vibrotactile thresholds as a function of frequency and duration. Perception \& Psychophysics, 22, 100-103.

Geldard, F. A. (1960). Some neglected possibilities of communication. Science, 131, 1583-1588.

Gescheider, G. A., Bolanowski, S., Hall, K., Hoffman, K., \& VerRILLO, R. (1994) The effects of aging on information-processing channels in the sense of touch: I. Absolute sensitivity. Somatosensory Motor Research, 11, 345-357.

Gescheider, G. A., Capraro, A. J., Frisina, R. D., Hamer, R. D., \& VERrillo, R. T. (1978). The effects of a surround on vibrotactile thresholds. Sensory Processes, 2, 99-115.

Gescheider, G. A., Edwards, R. R., Lackner, E A., Bolanowski, S. J., \& Verrillo, R. T. (1996). The effects of aging on informationprocessing channels in the sense of touch: III. Differential sensitivity to changes in stimulus intensity. Somatosensory \& Motor Research, 13, 73-80.

Gescheider, G. A., Valetutti, A. A., Jr., Padula, M. C., \& Verrillo, R. T. (1992). Vibrotactile forward masking as a function of age. Journal of the Acoustical Society of America, 91, 1690-1696.

GILMER, B. vON H. (1966). Problems in cutaneous communication from psychophysics to information processing. New York: American Foundation for the Blind.

Goble, A. K., Collins, A. A., \& Cholewiak, R. W. (1996). Vibrotactile thresholds in young and old observers: The effect of spatial summation and the presence of a rigid surround. Journal of the Acoustical Society of America, 99, 2256-2269.

GoFf, G. D. (1967). Differential discrimination of frequency of cutaneous mechanical vibration. Journal of Experimental Psychology, 74, 294-299.

GreEn, B. G. (1977). The effect of skin temperature on vibrotactile sensitivity. Perception \& Psychophysics, 21, 243-248.

Greenspan, J. D., \& Bolanowski, S. J. (1996). The psychophysics of 
tactile perception and its peripheral physiological basis. In L. Kruger (Ed.), Pain and touch (2nd ed., pp. 25-104). San Diego: Academic Press.

HAMBURger, H. (1980). Locognosia: The ability to localize tactile stimuli on the body surface. Unpublished doctoral dissertation, University of Amsterdam, Tübingen.

Hautus, M. J., \& LeE, A. J. (1998). The dispersions of estimates of sensitivity obtained from four psychophysical procedures: Implications for experimental design. Perception \& Psychophysics, 60, 638649 .

HILL, J. W. (1970). Describing function analysis of tracking performance using two tactile displays. IEEE Transactions on Man-Machine Systems, MMS-11, 92-100.

Hollins, M. (1989). Understanding blindness. An integrative approach. Hillsdale, NJ: Erlbaum.

Hölzl, R., Stolle, A., \& KleinböHL, D. (2002, February). From the cutaneous rabbit to spatio-temporal maps. Presentation to the Naval Aerospace Medical Research Laboratory, Pensacola, FL.

Johnson, K. O., \& HsiaO, S. S. (1992). Neural mechanisms of tactual form and texture perception. Annual Review of Neuroscience, 15, 227-250.

Johnson, K. O., \& LAMB, G. D. (1981). Neural mechanisms of spatial tactile discrimination: Neural patterns evoked by Braille-like dot patterns in the monkey. Journal of Physiology, 310, 117-144.

Johnson, K. O., \& Phillips, J. R. (1981). Tactile spatial resolution: I. Two-point discrimination, gap detection, grating resolution, and letter recognition. Journal of Neurophysiology, 46, 1177-1191.

Johnson, K. O., Van Boven, R. W., \& Hsiao, S. S. (1994). The perception of two points is not the spatial resolution threshold. In J. Boivie, P. Hansson, \& U. Lindblom (Eds.), Touch, temperature, and pain in health and disease: Mechanisms and assessments (pp. 389403). Seattle: IASP Press.

KEIDEL, W. D. (1968). Electrophysiology of vibratory perception. In W. D. Neff (Ed.), Contributionsto sensory physiology (Vol. 3, pp. 1-79). New York: Academic Press.

Kenshalo, D. R. [S.] (1979). Aging effects on cutaneous and kinesthetic sensibilities. In S. S. Han \& D. H. Coon (Eds.), Special senses in aging. Ann Arbor: University of Michigan, Institute of Gerontology.

Kenshalo, D. R. S. (1986). Somesthetic sensitivity in young and elderly humans. Journal of Gerontology, 41, 732-742.

KLeinman, J. M., \& Brodzinsky, D. M. (1978). Haptic exploration in young, middle-aged, and elderly adults. Journal of Gerontology, 33, 521-527.

Larkin, W. D., Reilly, J. P., \& Kittler, L. B. (1986). Individual differences in sensitivity to transient electrocutaneous stimulation. IEEE Transactions on Biomedical Engineering, BME-33, 495-504.

LEVITT, H. (1971). Transformed up-down methods in psychoacoustics. Journal of the Acoustical Society of America, 49, 467-477.

LEWY, W. (1895). Experimentelle Untersuchungen über das Gedächtnis. Zeitschrift für Psychologie, 8, 231-292.

Lindblom, U., \& VerRillo, R. T. (1979). Sensory functions of chronic neuralgia. Journal of Neurology, Neurosurgery, \& Psychiatry, 42, 422-435.

Linster, C., \& Cleland, T. (2001). How spike synchronization among olfactory neurons can contribute to sensory discrimination. Journal of Computational Neuroscience, 10, 187-193.

Millar, S. (1985). The perception of complex patterns by touch. Perception, 14, 293-303.

Miller, G. A. (1956). The magical number seven, plus or minus two: Some limitations on our capacity for processing information. Psychological Review, 63, 81-97.

Mirsky, I. A., Futterman, P., \& Broh-Kahn, R. H. (1953). The quantitative measurement of vibratory perception in subjects with and without diabetes mellitus. Journal of Laboratory \& Clinical Medicine, 41, 221-235.

Montagna, W. (1965). Morphology of the aging skin: The cutaneous appendages. In W. Montagna (Ed.), Advances in biology of skin: Aging (Vol. 6, pp. 1-16). New York: Pergamon.

Oestreicher, H. L. (1951). Field and impedance of an oscillating sphere in a viscoelastic medium with an application to biophysics. Journal of the Acoustical Society of America, 23, 707-724.
PARRISH, C. S. (1897). Localization of cutaneous impressions by arm movement without pressure upon the skin. American Journal of Psychology, 8, 250-267.

Pearson, G. H. J. (1928). Effect of age on vibratory sensibility. Archive of Neurology \& Psychiatry, 20, 482-496.

Phillips, J. R., Johansson, R. S., \& Johnson, K. O. (1992). Responses of human mechanoreceptive afferents to embossed dot arrays scanned across fingerpad skin. Journal of Neuroscience, 12, 827-839.

Pubols, B. H., JR. (1987). Effect of mechanical stimulus spread across glabrous skin of raccoon and squirrel monkey hand on tactile primary afferent fiber discharge. Somatosensory Research, 4, 273-308.

Rabinowitz, W. M., Houtsma, A. J. M., Durlach, N. I., \& Delhorne, L. A. (1987). Multidimensional tactile displays: Identification of vibratory intensity, frequency, and contactor area. Journal of the Acoustical Society of America, 82, 1243-1252.

Raj, A. K., McGrath, B. J., Rochlis, J., Newman, D., \& Rupert, A. H. (1998, June). The application of tactile cues to enhance situation displays. Presentation at the Third Annual Symposium and Exhibition on Situational Awareness in the Tactical Air Environment, Piney Point, MD.

Raj, A. K., Roetzer, L. M., Fatolitis, P. G., Cholewiak, R. W., \& KASS, S. J. (2001, January). Haptic interfaces to augment human machine interactions in space activities. Paper presented at the Bioastronautics Investigators' Workshop, Galveston, TX.

Reed, C. M., \& Durlach, N. I. (1998). Note on information transfer rates in human communication. Presence, 7, 509-518.

Rogers, C. H. (1970). Choice of stimulator frequency for tactile arrays. IEEE Transactions on Man-Machine Systems, MMS-11, 5-10.

Rupert, A. H. (2000). Tactile situation awareness system: Proprioceptive prostheses for sensory deficiencies. Aviation Space \& Environmental Medicine, 71(9, Suppl.), A92-A99.

Rupert, A. H., Guedry, F. E., \& ReschKe, M. F. (1993, October). The use of a tactile interface to convey position and motion perceptions. Paper presented at the NATO Advisory Group for Aerospace Research and Development (AGARD), Lisbon.

SCHIMIRGK, K., \& RÜTTINGER, H. (1980). The touch corpuscles of plantar surface of the big toe: Histological and histometrical investigations with respect to age. European Neurology, 19, 49-60.

SEnders, V. L. (1958). Measurement and statistics. New York: Oxford University Press.

SHERRICK, C. E. (1985). A scale for rate of tactual vibration. Journal of the Acoustical Society of America, 78, 78-83.

Sherrick, C. E., Cholewiak, R. W., \& Collins, A. A. (1990). The localization of low- and high-frequency vibrotactile stimuli. Journal of the Acoustical Society of America, 88, 169-179.

Steinberg, F. U., \& Graber, A. L. (1963). The effect of age and peripheral circulation on the perception of vibration. Archives of Physical Medicine \& Rehabilitation, 44, 645-650.

Stevens, J. C. (1990). Temperature and the two-point threshold. Somatosensory \& Motor Research, 6, 275-284.

Stevens, J. C. (1992). Aging and spatial acuity of touch. Journal of Gerontology: Psychological Sciences, 47, P35-P40.

Stevens, J. C., Foulke, E., \& Patterson, M. Q. (1996). Tactile acuity, aging, and Braille reading in long-term blindness. Journal of Experimental Psychology: Applied, 2, 91-106.

Stevens, J. C., \& Patterson, M. Q. (1995). Dimensions of spatial acuity over the life span. Somatosensory \& Motor Research, 12, 29-47.

Summers, I. R., \& Chanter, C. M. (2002). A broadband tactile array on the fingertip. Journal of the Acoustical Society of America, 112, 2118-2126.

Tan, H. Z., Durlach, N. I., Reed, C. M., \& Rabinowitz, W. M. (1999). Information transmission with a multifinger tactual display. Perception \& Psychophysics, 61, 993-1008.

TAWNEY, G. (1895). The perception of two points not the space-threshold. Psychological Review, 2, 585-593.

TAY LOR, B. (1977). Dimensional interactions in vibrotactile information processing. Perception \& Psychophysics, 21, 477-481.

VAllbo, Å. B., \& Johansson, R. S. (1984). Properties of cutaneous mechanoreceptors in the human hand related to touch sensation. Human Neurobiology, 3, 3-14.

Van Doren, C. L., Gescheider, G. A., \& Verrillo, R. T. (1990). Vi- 
brotactile temporal gap detection as a function of age. Journal of the Acoustical Society of America, 87, 2201-2206.

VERRILLO, R. T. (1966). Effect of spatial parameters on the vibrotactile threshold. Journal of Experimental Psychology, 71, 570-575.

VERRILLO, R. T. (1979). Change in vibrotactile thresholds as a function of age. Sensory Processes, 3, 49-59.

VERriLlo, R. T. (1980). Age related changes in the sensitivity to vibration. Journal of Gerontology, 35, 185-193.

VERRILlo, R. T. (1982). Effects of aging on the suprathreshold responses to vibration. Perception \& Psychophysics, 32, 61-68.

Verrillo, R. T. (1985). Psychophysics of vibrotactile stimulation. Journal of the Acoustical Society of America, 77, 225-232.

VerriLlo, R. T. (1993). The effects of aging on the sense of touch. In R. T. Verrillo (Ed.), Sensory research: Multimodal perspectives (pp. 285-298). Hillsdale, NJ: Erlbaum.

Verrillo, R. T., \& Bolanowski, S. J. (1986). The effects of skin temperature on the psychophysical responses to vibration on glabrous and hairy skin. Journal of the Acoustical Society of America, 80, 528532 .

Verrillo, R. T., Fraioli, A. J., \& Smith, R. L. (1969). Sensation magnitude of vibrotactile stimuli. Perception \& Psychophysics, 6, 366372.

Vierordt, K. (1870). Die Abhängigkeit der Ausbildung des Raumsinnes der Haut von der Beweglichkeit der Körpertheile. Zeitschrift für Biologie, 6, 53-72.

WAhren, L. K., \& TorebJork, E. (1992). Quantitative sensory tests in patients with neuralgia 11 to 25 years after injury. Pain, 48, 237-244.

Weber, E. H. (1978). The sense of touch (De Tactu, H. E. Ross, Trans.; Der Tastsinn, D. J. Murray, Trans.). New York: Academic Press. (Original work published 1826)
Weinstein, S. (1968). Intensive and extensive aspects of tactile sensitivity as a function of body part, sex, and laterality. In D. R. Kenshalo (Eds.), The skin senses (pp. 195-222). Springfield, IL: Thomas.

Weisenberger, J. M. (1992). Communication of the acoustic environment via tactile stimuli. In I. A. Summers (Ed.), Tactile aids for the hearing impaired (pp. 83-109). London: Whurr.

Weisenberger, J. M., \& Percy, M. E. (1995). The transmission of phoneme-level information by multichannel tactile speech perception aids. Ear \& Hearing, 16, 392-406.

WhANGER, A. D., \& WANG, H. S. (1974). Clinical correlates of the vibratory sense in elderly psychiatric patients. Journal of Gerontology, 29, 39-45.

WILSKA, A. (1954). On the vibrational sensitivity in different regions of the body surface. Acta Physiologica Scandinavica, 31, 285-289.

WinkelmanN, R. K. (1965). Nerve changes in aging skin. In W. Montagna (Ed.), Advances in Biology of Skin: Aging (Vol. 6, pp. 51-61). New York: Pergamon.

Woodward, K. L. (1993). The relationship between skin compliance, age, gender, and tactile discriminative thresholds in humans. Somatosensory \& Motor Research, 10, 63-67.

ZELENÁ, J. (1994). Nerves and mechanoreceptors. London: Chapman \& Hall.

Zwislocki, J. J., Maire, F., Feldman, A. S., \& Rubin, H. (1958). On effects of practice and motivation on the threshold of audibility. Journal of the Acoustical Society of America, 30, 254-262.

(Manuscript received November 12, 2002; revision accepted for publication March 19, 2003.) 